\title{
Polish Energy Policy 2050 - an instrument to develop a diversified and sustainable electricity generation mix in coal- based energy system
}

\author{
Michal Wierzbowski ${ }^{\text {* }}$, Izabela Filipiak ${ }^{\mathrm{a} * *}$, Wojciech Lyzwa ${ }^{\mathrm{a}}$
}

${ }^{\text {a} L o d z ~ U n i v e r s i t y ~ o f ~ T e c h n o l o g y, ~ 90-924 ~ L o d z, ~ P o l a n d ~}$

\begin{abstract}
Polish economy is still undergoing the transformation process and seeks to converge with the most developed economies in Europe. While many economic reforms have been made, the generating sector was left to its own devices and lack of the investments caused that electricity supply in Poland is ineffective and not secure. The coal is a primary fuel and it constitutes over $80 \%$ of the energy mix. Thus, with energy mix restructuration ahead, the ambitious and balanced energy policy is highly required.

The article aims to present the 2050 Energy Policy for Poland, which should facilitate the transformation of coal-based electricity generation system towards more sustainable and diversified energy mix. Comprehensive description and review of the current conditions of energy sector in Poland are accompanied with strengths and problems that need to be solved, taking into account European requirements. Additionally, in the paper the authors describe the development process of the Polish Energy Policy as they actively participated in the calculations of optimal energy mix for Poland. The manuscript presents the $e$ Mix model (energy mix optimization tool) developed by the authors, that constituted a background for Ministry of Economy to create Energy Policy. Hundreds of simulations scenarios were performed for the Ministry of Economy to provide the clear view of the electricity generation sector and to understand the impacts of all external stimuli to the mix. Assumptions for the model and results of calculations according to the policy scenarios are presented in the paper. Finally, the authors evaluate the final decisions of the policy makers, integrated in the Polish Energy Policy 2050, taking into account the challenges for the Polish power sector.
\end{abstract}

Keywords: energy policy, sustainable development, enegy mix, optimization, computer modelling, transition country

*+48503033 225, michal.wierzbowski@p.lodz.pl

**+48 602296 055, izabela.filipiak@ dokt.p.lodz.pl 


\section{List of abbreviations}

bcm - billion cubic meters

CHP - Combined Heat and Power

DSR - Demand Side Response

EC - European Commission

ETS - EU Emissions Trading System

EU - European Union

EUA - European Union Allowances

GDP - Gross Domestic Product

HVDC - High Voltage Direct Current

IEM - Internal Energy Market

LNG - Liquid Natural Gas

(n)CDGU - (not) Centrally Dispatched Generating Units

PV - Photovoltaics

PEP 2050 - Polish Energy Policy 2050

PSE - Polish Transmission System Operator

RES - Renewable Energy Sources

TSO - Transmission System Operator

\section{Table of content}

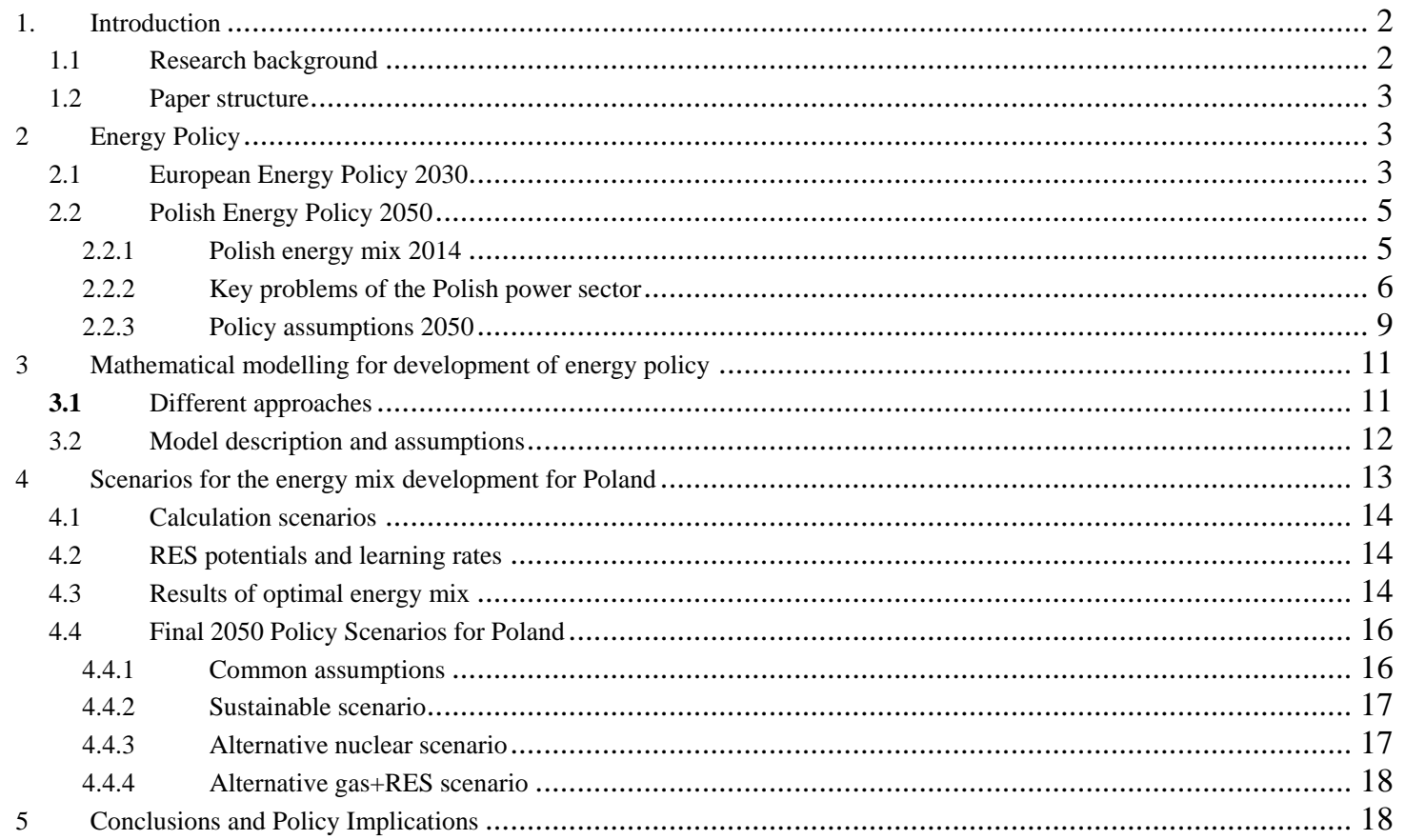

\section{Introduction}

\subsection{Research background}

The paper provides the description of the most recent Polish Energy Policy 2050. Currently, Poland is in the middle of its economy transformation. Having one of the biggest GDP growth in Europe (3.6 \% in 2015, while average in EU did not surpass $1.9 \%$ [1]), Polish economy is considered as secure and stable, even in the face of recent disturbances and financial crises (see Poland's ratings for 2015 i.e.: [2]). Nevertheless, maintaining the current development rate requires significant reforms and new strategic thinking. Energy sector is crucial for the further progress and although some reforms of the electricity markets were already made (liberalization, Third Party Access, unbundling etc.), there were little investments in the generation sector (see chapter 2.2.2.). Current situation of the Polish energy sector, particularly power sector, is not optimistic. Pol- 
and faces the regular shortages of the power system reserves and missing capacity problems. In August 2015, polish TSO limited the electricity consumption for the industry [3]. New investments are not likely to be started, because of the very low prices at the wholesale electricity markets (average price in 2015 at the wholesale electricity market was around $36.34 € / \mathrm{MWh}$ [4], which was not attractive for investors). Moreover, the trend indicates further prices decrease due to the growth in renewable energy sources (RES) penetration in Poland.

Currently, the Polish energy mix relies on coal in over $80 \%$. About $5 \mathrm{GW}$ of power capacities must be commissioned until 2020, further $5 \mathrm{GW}$ until 2030 and 9 GW until 2040. Currently installed power capacity in Poland reaches $40 \mathrm{GW}$, and up to 2050, almost a half of it must be replaced with the new units. Additionally, as the polish economy is still converging, increase is electricity consumption is guaranteed and new additional assets must be constructed to cover the demand. Another problem of the Polish power system is stability and balancing issue caused by the intermittent generation. Hence, it can be said that the polish power sector is currently in transformation and many actions must be undertaken to provide a secure electricity supply for the citizens and industry. From this perspective, the case of polish energy mix, its energy policy and the transition to low emission economy is very interesting.

The paper presents the assumptions for the 2050 Polish Energy Policy (PEP 2050) but also describes the backstage of the policy development, as the authors of the manuscript took active part in the process. Their role was to act as consultants on the technical aspects of the power system operation and to predict the results of the Polish energy mix optimization. For that purpose, the analytical tool - eMix programme [5], [6] - was developed. It is an optimization model, designed by the authors of the manuscript in cooperation with the Department of Energy of the Ministry of Economy of the Republic of Poland. After the development stage, the $e$ Mix served for calculating dozens of scenarios to find the most optimal solutions for Poland. The manuscript presents the main assumptions and features of the $e$ Mix and describes the results of the energy mix optimization that formed a basis for PEP 2050 assumptions.

\subsection{Paper structure}

The paper begins with the motivation for its creation that shortly describes the major problems of power sector. Since Poland is a part of European Union and Polish policy must be coherent with EU policies, there is the brief description of the European power sector and European Energy policy 2030 (Section 2.1). This part also mentions the idea of Emissions Trading System (ETS) and Internal Energy Market. The section 2.2. comprehensively presents the Polish Power sector with all the challenges that need to be addressed in the nearest future. Then, there is a description of the Polish Energy Policy 2050 and its operational objectives and priority projects. Section 3 was developed to present the already existing approaches to energy system modelling used for the policy development and the $e$ Mix model assumptions. Section 4 starts with the calculation of the scenarios implemented in the $e M i x$ model with their main results: installed power structure and electricity generation up to 2050, $\mathrm{CO}_{2}$ emissions, primary fuel consumption, total and marginal cost of electricity generation. This part is followed by the presentation of scenarios included in the Polish Energy Policy 2050. The article is summarized with conclusions and policy implications.

\section{Energy Policy}

The energy mix represents the share of particular technologies used to meet the energy demand. Energy Policy should guide to achieve the most beneficial energy mix from the energy security perspective. Although the presented Policy influences the whole economy of the country (electricity, heat, transportation etc.), the main problem addressed in the article is the electricity sector. Consequently, the following information is mostly related to the electricity production rather than whole energy sector. Polish Energy Policy 2050 was developed in accordance with the European Energy Policy 2030, thus the brief description of European Policy assumption is also presented in the article.

\subsection{European Energy Policy 2030}

The exploitation of the primary energy in the EU-28 countries is constantly decreasing. It is the result of the gradually shrinking supplies but also of the fact that the extraction of raw materials is uneconomical on a small scale. Almost all energy sources have decreased their production and the total production of the primary energy in 2014 equaled 770.7 million tonnes of oil equivalent, which represents the drop by $17 \%$ in ten years. The decrease in primary production is not so problematic, since the increased amount of electricity is being 
produced from RES. In 2014 around 24\% of electricity generation derived from unconventional sources (Figure 1) [7].

The deficiency that results from the decline of energy production must be met through the import. In 2014, $53.5 \%$ of the gross energy consumption among the EU countries was imported from the non-European countries. The EU-28's imported 881 millions toe more than exported [8]. Each EU-28 country (in spite of Denmark) must import energy to cover the demand, yet the index of imported energy was higher in the most populous countries (Germany, France, United Kingdom, Italy or Spain). Most of the imports of crude oil come from OPEC countries and Russia. The gas is mostly supplied by Russia, Norway and Algeria.

The energy security of EU-28 relies heavily on the relationship with their neighbors, mostly Norway and Russia. EU spent $€ 300$ billion in 2013 on importing crude oil and its derivatives of which one third goes to Russia. Six member countries import the gas only from Russia and three among them use the gas fired power stations to cover quarter of their total domestic demand [9]. The uncertain relations between trading or transit countries and Russia may pose a threat to the reliability of raw materials supply in Europe. The gas conflict between Russia and Ukraine in 2009 made the situation even more alarming. To mitigate the consequences of the possible suspension of supplies, the Council of the European Union released the "Directive 2009/119/EC of 14 September 2009 imposing an obligation on Member States to maintain minimum stocks of crude oil and/or petroleum products" [10]. The obligatory stocks should cover the equivalent of the higher one of the following quantity:

- Enough to cover 90 days of daily imports (average)

- Enough to cover 61 days of inland consumption (average)

The daily imports and inland consumption are converted to the crude oil equivalent calculated for the previous year (or for the obligations for the first quarter of the year for the last but one year) [7].

The dependence of European Union on the primary energy import is one of the biggest stimuli to constantly decrease the energy intensity of its economy and focus on the more ecological energy sources. Thus, the European Commission released "A policy framework for climate and energy in the period from 2020 to 2030" [11] in which it highlights the overall direction of the energy policy development for the nearest future. The climate and energy policies overall directions assume reaching the four main objectives:

- Improved competitiveness

- Security of supply

- Sustainability

- Low emissive economy

The 2030 directive is one of the guidelines that precisely established the targets to achieve above-mentioned objectives. It was elaborated to constitute the continuation of the " $20 / 20 / 20$ " policy. The following Table 1 presents the main goals of the 2020 and 2030 directives.

Because of the already taken measures related to the "20-20-20" policy, the target of $40 \%$ greenhouse gases reduction in 2030 is likely to be achieved. The predicted level of greenhouse gases reduction will probably reach about $32 \%$ in the 2020 . Thus, there is not much investments to be made in order to achieve the established goal for 2030.

The greenhouse gases reduction and increase of the share of RES are strongly related to each other. The first target should result in the increase of the share of RES by $27 \%$. The development of RES' share in the power sector is the easiest way to improve energy independence. The European Union is constantly exposed to the price fluctuations of the imported raw materials and fuels. Investments in this sector will not only limit the volatile expenditures on imported goods, but also stimulate the growth of innovative technologies and create new jobs. The share of RES in the energy industry is likely to exceed $45 \%$ by 2030 .

The energy efficiency 20-20-20 target, although very important (is very valuable to achieve the main objectives of the energy policies), probably will not be reached by 2020 .

To achieve the greenhouse gases reduction by $40 \%$ in 2030, the energy savings should be increased by $25 \%$. This could be realized by maintaining the level of investments in the industry and passengers' vehicles and increasing investments in housing sector, transport (other than passengers' vehicles) and electrical equipment. All those expenditures will on balance lead to the cuts in the running costs. They should also prompt the development of the technology and consequently the EU will maintain the leader position in the technology sector. The costs of adaptation to the new policy will affect mostly countries with lower GPD per capita. 
Those countries have usually lower energy efficiency; their energy production is based on the conventional, inefficient power generating units and thus, require greater investments in the energy sectors. It is calculated that the countries with the GPD factor lower than $90 \%$ of EU average should invest in the power sector approximately $€ 3$ billion a year more than the average EU country (from 2021 till 2030). The 2030 policy also defines the change in the ETS trading system and development of the internal energy market.

\section{ETS trading system}

The downturn of the economies during the crisis, among other reasons, resulted in the surplus of the allowances for the carbon dioxide emissions. The low price of allowances makes the whole system ineffective - it does not stimulate the investments in the low-emission energy sources and industry. To artificially increase the prices, the European Commission (EC) decided on withdrawing $€ 900$ million allowances for the years 2014-2016 and postpone them until 2019-2020 (so called backloading). Additionally, currently the phase four of the EU ETS is being discussed. Between 2020 and 2030, new rules for allowances allocation will be implemented. Free allowances will be limited only to the very specific cases, mainly to avoid 'carbon leakage'. Any further exemptions from the European Union Allowances (EUA) purchasing will be made only if equivalent of EUA value is paid to the low or zero-emissions technologies (Modernization Fund, NER400). As the backloading or occasional cancellation of EUA is not effective measure to increase the allowances' prices, EC decided on implementation of the Market Stability Reserve from 2021 that will cut of the surplus of allowances year by year to enhance the stability of the ETS system (increase the prices and stabilize the trends). It would also alleviate the consequences of the sudden but temporary growth of the demand that can result in carbon leakage (some high emissive companies may be interested in the assignment of its production to the countries with no ETS system).

\section{Internal Energy Market}

The conclusion of the Internal Energy Market (IEM) development is one of the highest priorities of the European Commission. The IEM would improve the energy security of European countries. First of all, it would diversify the foreign sources of primary energy for member countries. Secondly, it would require the increase in the number of interconnections and as a result allow for better management of the electricity distribution. Finally, it would reduce the growth of the electricity prices for households and enterprises. It is estimated that the fully integrated IEM could bring the savings of between $€ 40-70$ billion in comparison to current costs. The IEM will allow for terminating the subsidies for the well-developed technologies and RES after 2030. Hence, all the energy generating sources will be subjected to the equal market rules. IEM for the electricity will require significant investments in the infrastructure, mainly transmission networks and interconnectors, and implementation of new market designs including intraday markets and pan-European balancing market.

\subsection{Polish Energy Policy 2050}

\subsubsection{Polish energy mix 2014}

The average yearly electricity demand for Poland increased by $17.3 \%$ in comparison to 1990 and reached 154.9 TWh in 2014 [12]. At the same time, the electricity production increased by only $14.8 \%$ (Figure 2). During this period, the available average power reserves were satisfactory (excluding economy crisis in 2008), until 2014 when the first positive import/export balance appeared and $2.2 \mathrm{TWh}$ was imported from foreign countries [13]-[15].

Over $80 \%$ of electricity in Poland is produced from hard coal and lignite. The energy mix can be considered in two dimensions. The first one relates to the structure of the installed capacity, so the share of each particular technology, according to the capacity in the whole power system. The second dimension relates to the share of each particular technology in the final electricity generation. Both of them are extremely important, as the power system operation cannot be analyzed only in one dimension. The share of particular technologies in energy production in Poland diverges from the capacity installed structure (Figure 3). The share of lignite exceeds $34.63 \%$ to cover the underproduction of other sources, mostly RES and water power plants. According to the Yearly Coordination Plans prepared by the PSE (Polish Transmission Operator), the average capacity available in 2016 will equal 34457 MW while there will be 41426 MW [17] of capacity installed (Figure 4). 
Poland is still a developing country so the GDP is predicted to be still increasing in the next decades although with the declining pace. Despite the fact that the energy efficiency of the economy is in all likelihood going to improve (Figure), the total electricity demand will continue to grow (Figure 6).

According to all forecasts, the electricity demand will increase by approximately $50 \%$ in the next 30 years (Figure 6). Thus, the problem of missing capacity (see 2.2.2.6) will not decline with time and must be addressed as quick as possible to avoid blackouts [19], [20].

\subsubsection{Key problems of the Polish power sector}

The energy sector as being very vast and complicated structure faces a lot of problems. The main challenges are related to its infrastructure, economic and political issues - sometimes they concern more than one of those areas at the same time. In the following section the authors raised the questions of ageing and insufficient infrastructure, primary energy supplies, and basic financial problems appearing in the power sector in Poland.

\subsubsection{Decommissioning of power plants}

The recent inspection carried by Polish Supreme Audit Office released a report on the current situation of Polish energy sector and the forecasts on the future energy security. The main problem of Polish energy sector is the impending decommissioning of old units. The predicted lifetime of coal power plants is 40 to 45 years. $59 \%$ of turbo generators are over 30 years old. Next $16 \%$ are between 20 and 25 years. Only $25 \%$ of units were built in the recent 20 years. Even more alarming situation can be observed for the boilers of which over $63 \%$ is over 30 years old and only $20 \%$ is less than 20 years old (Figure 7) [23]-[25].

Figure 8shows the the historical data and the forecasts of power demand in Poland [23] . It is predicted that in 2035 the maximum demand on the power will reach $30 \mathrm{GW}$ and in the next 15 years it will probably exceed $38 \mathrm{GW}$. At this time, only $5 \mathrm{GW}$ of currently operating power generating units will be available. The rest of the required capacity must be covered by the new units. Between 2010 and 2014 there were declarations of building 10 units, but all of the investors withdrew their offers because of the high uncertainty of future income [26]. Reluctance to build new units may cause the deterioration of Polish energy security especially taking into account the schedule of decommissioning of currently existing units (Table 2).

Despite the emergency measures that can be taken by the PSE, the shortages of power available are predicted to appear inevitably. The first serious shortage appeared in the August 2015. High temperatures, low water levels, planned renovations and breakdowns (that in the crucial moment August, $10^{\text {th }}$ constituted one fifth of predicted demand in the morning peak) resulted in power cuts for the industry [29]. Such shortages are predicted to appear also in the nearest future. According to the calculations conducted by the authors, in the most realistic scenario, if nothing changes, the $9 \%$ of required level of power reserves will not be available most times (excluding 2019 and 2020 when new generators start operation) and 18\% of power reserves will not be available at all (Figure 9). What is more, the power deficits may appear in 2016 autumn and then from 2022 they will gradually deepen significantly (Figure 10). It is worth highlighting, that the analysis, which results are presented below, assumes that the TSO can still benefit from so called 'cold reserve'. It is a type of ancillary service, introduced to maintain in the reserves of $830 \mathrm{MW}$ supplied by several units that should already be decommissioned. The TSO is going to maintain this service until 2017 or even 2018 and 2019, although the reliability of this power is limited (in August 2015, when Poland faced power cuts, none of the units in "cold reserve" were able to start up).

The investors claimed that by 2028 , they are going to spend over $€ 13$ billion on creating additional 10.5 GW of capacity and around $€ 2.8$ billion on refurbishing existing units [26]. Those numbers, however impressive, are not sufficient. The energy security in the nearest, as well as in the more distant future, will be maintained only if fast actions are taken. Some regulations need to be introduced, even though they may distort competition and introduce additional costs. It is predicted, that between 2020 and 2035, as a result of the energy shortages and its social implications, the total loses of losing energy security are going to reach over $€ 16$ billion. This is why even cost-generating actions taken by the government are relatively profitable [26]. Decisions about supporting the investments in the electricity sector such as capacity remuneration mechanisms should be made as soon as possible in order to avoid the giant costs of undelivered energy.

The alarming situation in the Polish energy sector was also described by numerous foreign institutions. In 2015, the World Economic Forum released a report [31] in which it evaluated 125 economies on the energy 
sector impact on economy growth, environmental sustainability and security. Poland received 0.65 EAPI index, which placed it at the end of the list of well developed countries. It reflects the urgent need to improve the situation in the Polish energy sector. According to ENTSO-E [32], Poland was the only European country threatened to loose adequacy in the 2015-2016 winter period. It points out the weak interconnection, danger caused by unplanned flows of energy through Poland (loop-flows) and insufficient level of power reserves in the hot, summer periods.

\subsubsection{Weak transmission network}

As of 31.12.2015 Polish transmission network consists of three types of high voltage lines [33]:

- $750 \mathrm{kV}: 114 \mathrm{~km}$

- $400 \mathrm{kV}: 5984 \mathrm{~km}$

- $220 \mathrm{kV}: 7971 \mathrm{~km}$

- $450 \mathrm{kV}$ DC (interconnection with Sweden): $254 \mathrm{~km}$

$70 \%$ of transmission lines is over 30 years old, and $47 \%$ over 40 years old [34], [35]. However, the maintenance processes prolonged the period of efficient functioning of transmission lines to 70 years, so the problem of old lines have been postponed. Although the average age of Polish transmission lines is below the one in Switzerland or Germany, the transmission and distribution system must deal with many other problems. Almost $66 \%$ of transmission and distribution lines are the overhead lines that are subjected to severe weather conditions (typical to Polish climate) that often cause damages [23].

The grid's density is not equal on the Polish territory - it is more expanded on the south and less in the north. The uneven structure causes that the grid operates in the "open" configuration instead of the meshed one and the possibilities of reconfiguration are limited. Polish grid allows for only one-way electricity flows and limits the potential of distributed generation. The frequent thefts of the infrastructure constantly increase the expenses of the operators [36]. The transmission loses are very substantial in the Polish energy sector: the total loss of electricity transmission in 2011 reached $10774 \mathrm{GWh}(7.3 \%$ of total electricity produced) which represents the loss of almost $€ 0.5$ billion [37]

Poland has 10377 MW of interconnections available with Germany, Czech Republic, Slovakia, Ukraine, Belarus, Lithuania and Sweden (Table 3). The connections with Sweden and Lithuania are made through DC Links. What is worth mentioning, in 2015, Lithuania finished the undersea 700 MW HVDC interconnection (NordBalt) with Sweden. This investment is also important for Poland, since the connections between Poland, Lithuania and Sweden create so called Baltic Ring which increase possible energy transmissions between those countries [38], [39].

Despite the large potential capacities of the interconnectors, which constitute the $25 \%$ of the installed generating capacities in the Polish national power system, the real possibilities of their utilization is strongly limited due to the loops flows. They are caused by the wind generation farms in Germany and not properly designed trading zones in the eastern and central Europe. Electricity traded by the German trading companies are executed through the Polish grid, blocking the capacities. The only fully controllable interconnectors in the Polish power system are HVDC links with Sweden (600MW) and recently commissioned interconnection with Lithuania (500MW). The shifting transformers (that are currently being installed) at a transmission line between Poland and Germany should enable the control over power flow (1500 MW for export and $500 \mathrm{MW}$ for import). Nevertheless, the transformers are to be installed only on one connection with Germany, while effective control can be obtained only by installing them at the entire synchronous connection and removing bottleneck in the western part of Polish transmission system.

\subsubsection{Gas uncertainty}

All scenarios of the polish power system development, considering increase of the prices of $\mathrm{CO} 2$ allowances, indicate the need for transformation towards gas-fired conventional units. Such power plants are able to balance the intermittent generation, since CHP gas-fired units are fully switchable (electricity only or heat only operation is possible) and emit moderate amount of $\mathrm{CO} 2$. Additionally, the investments costs are the lowest among currently known technologies and a unit can be constructed within two years, what limits the financial costs. The crucial problem is gas availability and its prices. 
Polish natural gas fields are estimated to have proven reserves of 140059 billion $\mathrm{m}^{3}$ (as of December 2012) according to [24] and 0.1 trillion $\mathrm{m}^{3}$ (for 2014) according to [42]. The proven reserves allow for over 23 years of extraction, if production were to continue at current rate. Polish gas consumption (mainly for heating and chemical industry) in 2014 equaled over $16 \mathrm{bcm}$ of which almost $4.47 \mathrm{bcm}$ derived from domestic sources and $11.65 \mathrm{bcm}$ were imported [43]. The share in the primary energy balance is growing - in 2011 it constituted $11.1 \%$ and it increased to $13 \%$ in 2015 , this tendency is likely to continue[21], [24], [42].

Estimates of the Polish resources of technically recoverable shale gas vary from 38.1 billion $\mathrm{m}^{3}$ [44] to 768 billion $\mathrm{m}^{3}$ [24], [45], or even very optimistic 4188 billion $\mathrm{m}^{3}$ [46]. So extreme discrepancy makes relying the Polish gas security on this doubtful source very risky. In addition, as of today, those deposits are impossible to economically extract with available technology and there is no proof that they will be in the foreseeable future. Another problem results from the use of controversial but the least expensive technology for the shale gas extraction - hydraulic fracturing. Investors' initial interest and optimistic approach to concessions and exploration of the Polish shale gas are becoming more and more cautious. Most of them have already delayed exploration activity to the unspecified future [47], [48]. Thus, Poland can solely rely on the domestic deposits and gas imported.

Although the gas prices in Europe are constantly declining, Polish expenses on gas imports are relatively high. Poland in 2010 prolonged the Yamal contract with Russia on gas imports, that obliged Poland to buy 10.2 billion cubic meters of gas a year (till 2022) of which $85 \%$ is contracted in a take or pay system. Additionally, the price contracted is one of the highest price in Europe (on average $23 \%$ higher than the one in western countries [49]). The prices of gas across the Europe decreased significantly recently, because of the decrease of crude oil prices. Although the details of the gas contracts are classified, it was revealed that the Russian gas price for Poland equaled 227.4 USD per $1000 \mathrm{~m}^{3}$ in the last quarter of 2015 [50]. The price discrimination results from overusing market power of monopolistic Gazprom. In past, most of the Polish gas imports were coming from Polish natural supplier - Russia. Although Polish gas transmission system is still oriented on importing gas from east, the situation is constantly changing due to deeper and deeper liberalization of the gas sector and expansion of gas market. Although the gas exchange in Poland is developing, the liquidity of the market is still insufficient.

Poland is a transition country for Yamal-Europe pipeline with transition capacity of $33 \mathrm{bcm}$ per year (Figure 11). Given to the new infrastructure in Wloclawek and redevelopment of Mallmow metering station on the German side, Poland may import gas from the west through the virtual and physical reverse $(5.5 \mathrm{bcm}$ of fixed flow and additional $2.7 \mathrm{bcm}$ of interruptible flow). Additionally, there is a possibility to import $1.5 \mathrm{bcm}$ through Lasow and $0.5 \mathrm{bcm}$ from Czech Republic. In case of suspension of gas supplies it is already possible to cover about even $90 \%$ of demand. The recently opened and soon to be exploited LNG gas terminal in Swinoujscie makes it possible to import additionally up to $5 \mathrm{bcm}$ of LNG a year (with perspective of extension to $7.5 \mathrm{bcm}$ a year) [51]. Poland has already signed in 2009 a contract for 1.5 billion $\mathrm{m}^{3}$ of LNG for 20 years with Qatar. Although the price for Qatar's gas is higher than Russian, it is still beneficial to differentiate the sources of this fuel. Furthermore, in Poland there are nine storage facilities owned by one company PGNiG. Seven of them store high-methane natural gas (over $2.5 \mathrm{bcm})$ and two of them store nitrogen-rich gas $(0.23$ bcm) [52]. Given all the opportunities available, the actual dependence on Russian gas is decreasing and Polish prospects to negotiate terms of Yamal contract are becoming more and more real.

\subsubsection{High price of domestic coal}

Polish reliance on coal (hard coal and lignite) as the primary fuel for electricity and heat production is not unjustified. Poland has large own supplies of those fuels. As of 31.12.2013, the total geological resources of coal are presented in Table 4.

In 2015, according to data supplied by Agency of Industry Development [54], Polish mines produced $72.2 \mathrm{Mt}$ of coal (0.3 Mt less than in 2014), sold 73.6 Mt (3.3 Mt more than in 2014) and 5.8 Mt were stored (3.6 Mt less than in 2014). Despite the increase in sale and significant decrease of employment (over 10 thousand employees less than in 2014 with almost the same level of output) the financial results of the sector were still dramatic. It is estimated, that in 2015 Polish mining sector lost out over $€ 460$ million [55]. It is caused by high cost of coal production and the uneconomical structure of employment. In $201351.2 \%$ of cost was incurred on the employment and $17.6 \%$ on external services [56], [57]. Because of this high inefficiency, since last quarter 2015 the price of extraction of a tone of hard coal was around 240 PLN - around 61 USD. Neverthe- 
less, the average world-market hard coal prices in January 2016 was around 46 USD/t in AmsterdamRotterdam-Antwerp and 50.25 USD/t in Richards Bay in RPA [58] (approximately $25 \%$ lower than the previous year). The decrease of the coal prices is caused by the reduction of coal consumption in China and warm winters that recently can be observed [59].

The situation of Polish mining sector is not going to improve in the nearest future. The market price of coal will constantly decrease as well as domestic consumption (because the efficiency of electricity generation gradually increases, and part of the share of coal in Polish energy mix must be replaced by low emissive technologies). Thus, the cost reduction is essential if Poland does not want to close its mines or constantly subsidize this sector.

\subsubsection{Energy from RES}

In $201414.8 \%$ of capacity was installed in RES (6028 MW). As a result, RES were responsible for $8 \%$ of total electricity production $(13388.26 \mathrm{GWh}$ ). The structures of capacity installed in RES and their electricity production are presented in Figure 12 [60], [61].

$64 \%$ of power production from RES fell to wind energy and next $17 \%$ to solid biofuels (Figure 12). For many years, cofiring of biomass became a cheap and easy way to increase revenues (because it was subsidized by a mechanism of 'green certificates' - a kind of guarantee of origin system) and reduced the theoretical CO2 emissions (because it was treated as 'zero emissive' fuel). It was predicted that it would trigger large investments in biomass production in Poland, which was supposed to develop the agriculture sector, but despite high potential [62], it turned out that it is more profitable to import biomass from abroad [63]. In $201411.7 \%$ of solid biofuels consumption was imported (mainly from eastern Europe countries but also from Germany, Spain, Greece, Indonesia, Liberia, Togo, Ghana and others [64]-[66]), as a result, instead of supporting Polish economy, huge amount of money was transferred abroad. In addition, cofiring of biomass decreases the efficiency and lifetime of boilers that were primarily designed for coal-only combustion [67]. As a result, it is possible, that in the nearest future the decommissioning of old units will cause the decrease of total domestic energy production from RES which may result in not fulfilling European Union's recommendations [68].

\subsubsection{Missing money and missing capacity problem}

As it was described in the Section 2.2.1, Polish power system needs immediate investments in new generating units. Existing conventional power plants have high fixed and variable costs (in comparison to subsidized wind energy with almost no variable costs). At the same time, the low prices of energy on the wholesale market (Table 5) and highly variable generation of those units (that are not designed to operate in such conditions) (Figure 13) cause that the generators are facing so called missing money problem (inability to cover their costs).

Their decreased time of operation does not allow for covering all expenses from the revenues from energy only market. The unpredictability of revenues deters potential investors, or even lead to closure of existing, inviable units, so the Polish power sector in the nearest future is going to face missing capacity problem - the situation in which not enough capacity is installed in the system to cover the demand [70]. First power outages appeared in August 2015 when high temperatures and low water levels on top of planned and unplanned outages (that exceeded $20 \%$ of predicted energy consumption in the morning of 10 August) caused the reduced available electricity supply for industrial users [71]. In the consecutive years, the power unbalances are likely to appear continuously [26], [72].

\subsubsection{Policy assumptions 2050}

The main targets of Polish Energy Policy 2050 (PEP 2050) were intended to create conditions for constant and sustainable development of the energy sector that should contribute to the economy growth, provide energy security in Poland and meet the energy demand of Polish enterprises and households. Proposal of the PEP 2050 was developed with assistance of the Advisory Team, which part were the authors of the manuscript.

The proposal consists of (a) Polish Energy Policy 2050, (b) Assessment of the PEP 2030, (c) Action Plan for 2015-2018, (d) Environmental Impact Assessment of PEP 2050 and (e) Perspective View for the Polish Energy Sector in 2050 - conclusions from the simulation analyses. The part "e" consists of the analyses prepared by the authors of this manuscript. 
To achieve the main targets of the Policy, three separate operational objectives have been established (Table 6). The energy security, competitiveness of Polish economy and environment protection are the most important issues that must be taken into consideration while thinking about power sector development.

The operational objectives are very general and just point the imprecise measures (such as 'limiting pollutions') to achieve them. More detailed guidelines are presented in the nine priority projects that are listed below:

\section{Effective utilization of domestic solid fuels sources}

Since Poland has its own resources of hard coil and lignite - the energy generation must be based on those fuels to increase independency on foreign supplies.

The decreasing prices of hard coal in the world have reduced the competitiveness of Polish supplies. There is an urgent need for reducing the costs of Polish mining sector, otherwise Polish coal supplies would not translate into energy security. It is predicted that the development works of new ways of using coal for energy production will be intensified, what would ensure the availability of different technologies such as coal gasification or liquefaction. Gasified coal could constitute a substitution for the natural gas imports. Simultaneously, there are many works connected with development of better technologies for using the byproducts of coal extraction such as methane, water and heat.

II. Improvement of energy efficiency (including CHP)

The overall energy efficient index will be increased thanks to new highly efficient power generating units that will consequently replace older assets. It is also important to maximize the time of the operation of the efficient units during the year. Additionally, the grid losses should be minimized. Current grid loses in Poland reach $6.9 \%$, while the average EU loses do not exceed 5.7\%. Grid loses can be reduced through modernization and replacement of currently existing lines, replacement of electrical substations by more efficient ones, development of distributed generation and increase of the efficiency of final energy use.

The improvement of energy efficiency can be carried through the change in heat production and distribution. $75 \%$ of energy for the heating should be coming from CHP power stations, otherwise $50 \%$ of it should come from RES or waste heat. The district heating modernization or replacement in some cases and building insulation would contribute to the energy efficiency through the limitation of the heat loses. In the long-term perspective it is important to increase the popularity of low-energy buildings and household appliances.

\section{Building nuclear power plant}

According to PEP2050 part of the capacity installed in the Polish power sector will be covered by the nuclear power plant of minimum 6000 MW [74]. Although the project works have been already launched, the final rated power has not been yet finally specified, and the start of operation is constantly being postponed (according to different sources is scheduled for 2029 or even 2031) [75], [76].

\section{Unconventional gas}

In the long-term perspective, the unconventional deposits of natural gas can play a crucial role in increasing the competitiveness of Polish economy. Thus, the works on searching the shale gas in Poland should be continued.

\section{RES penetration}

The increase of share of RES in the energy mix in Poland should be maintained. However, it is important to limit the impact of RES on the stability of energy sector. Thus, the techniques of energy storage or weather forecasting should be developed to make the RES generation more predictable and controllable. All subsidies for RES should be withdrawn by 2035 . Polish energy sector by this time should develop a technique of renewable electricity generation that would be perfectly adjusted to Polish conditions and potential.

VI. Prosumers 
Thanks to the further deregulation of energy sector as well as increasing accessibility and affordability of micro power plants, the resell of excessive electricity produced by private households will be possible. This phenomenon should be followed by the development of smart grids, that are adjusted to the distributed generation.

VII. Smart grid

The development of the transmission and distribution systems should also consider introducing smart grids and smart metering systems. It would allow for better communication between energy recipients and providers. Real time price signals would also increase the potential of DSR. The smart grid would allow for better management of grid, which result in increasing its security and reducing the costs of exploitation.

VIII. Interconnections

The development of the interconnections should be carried on three fields:

- Diversification of sources and directions of import of crude oil,

- Development of transmission grid interconnections,

- Diversification of sources and directions of import of natural gas. In the short-term perspective it is connected to finalizing the Swinoujscie LNG Terminal, in further perspective it is planned to construct the gas pipelines (provided for in the trans-European networks program).

\section{Development of power generating assets}

Current analyses indicate the urgent need to increase the available capacity in the power system. The financial and regulatory incentives allocated to RES and cogeneration units, the need of purchasing $\mathrm{CO} 2$ emission allowances and relative stabilization of electricity prices resulted in the reluctance of the investors to build new assets. Thus, to avoid missing capacity problem some mechanism to mitigate investment risks and increase the profitability of the investments in conventional and nuclear energy sector must be implemented.

One of the appendices to PEP 2050 [24] describes the Action Plan to achieve policy targets. It directly settles the tasks to achieve three main targets of PEP 2050 (operational objectives). Nevertheless, the action plan covers only the period $2015-2018$ and it lacks the long-term strategic vision. The time constants in the energy sector are much longer than for other industries and therefore its problem cannot be solved or planned to be solved only in short-term perspective.

\section{Mathematical modelling for development of energy policy}

In the entire economy almost all sectors depend on each other (directly or indirectly). In order to assess the impact of any policy it is important to analyze its impact on the sector itself and then on the whole economy. In most cases both tasks: sector analyses and cross-sector analyses, the economics provides tools that can be successfully used. However, there are some sectors of the economy, that cannot be analyzed and for which the policy impact cannot be assessed only on the basis of econometric tools. These are the very technical branches such as energy and power sector. Primary objectives of these sectors operation relate to the technical standards and requirements, while the market rules are the secondary issue. Therefore, while assessing the impact of energy policy it is essential to properly investigate the sector operation and the effects of the policy on the sector itself. The second step may relate to impact assessment of the policy on the other sectors and entire economy. Analyzing the PEP 2050, the authors of the manuscript developed the sector model to define the directions of the energy policy for the power sector.

This chapter consists of a brief summary of the existing approaches to this task, that were considered in the development of model for optimization of Polish energy mix and description of the model itself.

\subsection{Different approaches}

Until now there have been many models developed for energy system modelling. Nevertheless, the need for appropriate model that would be able to represent the important technical details of the power system operation and face the challenges of twenty-first century energy systems (with high RES penetration) has not been satisfied yet [77]. It is essential for such models to link long-term energy planning with consideration of short- 
term variability of intermittent generation [78]. Connolly et al. made a review of models created to analyze the future operation of energy systems with renewable generation [79] and many scientists around the world are continuing researches on this topic.

Some of them are carrying researches over satisfying all energy needs from renewable generation in particular areas. The Ostegaard et al. analyze the possibility of covering $100 \%$ of energy needs of Aalborg Municipality in Denmark from renewable energy sources with commercial EnergyPLAN model (deterministic, inputoutput model) [80]. The same was done for whole Denmark [81], Ireland [82] and Macedonia [83]. Other researches examined the $100 \%$ RES penetration with other computation tools e.g. in [84] the authors are using $\mathrm{H}_{2}$ RES software (model for energy planning in isolated regions - further description in [85]) for Portuguese [84] power system or Mathlab for New Zeland's power system [86].

Other optimization models are used for power systems with mixed conventional and renewable generating assets. Tolis and Rentizelas [87] created quadratic programming optimization model for energy system planning (for case of Greece power sector) maximizing total Net Present Value subjected to social, and technical constraints taking into account electricity and emission allowances pricing. In [88] there is a linear programming model for electricity generation planning in Greece taking into account life cycle external cost. Tahir and Banares-Alcantara [89] used linear programming energy mix optimization model with knowledge representation module that transforms energy policy assumptions into equations representing technology preference. In [90] there is a description of Chinese power sector planning model minimizing the accumulated total cost with consideration of $\mathrm{CO}_{2}$ emissions mitigation. Pina et al. [91] developed hybrid modelling method for electricity systems development planning with high RES penetration (e.g. Portugal) using long-term TIMES and short-term EnergyPLAN. In [92] the authors decided on least-cost energy planning of United Arab Emirates energy system using linear MARKAL optimization model. MARKAL model was also used in [93] for energy system optimization to examine the impact of shale gas supply and energy policy on the USA system. In [94] the authors presented two-stage stochastic energy planning model taking into account financial risk related to over and underproduction (case study - sub sector in Ontario). [95] shows a MILP model for electricity generation optimization taking into account life cycle cost and environmental aspects. Another MILP model for transmission expansion planning (using Benders decomposition) is showed in [96]. MILP modelling was also used in [97] for generation expansion planning with sensitivity analysis (for Greece case study) calculating total electricity demand, total cost composition, power and electricity production structure, investment cost for newly-built, total $\mathrm{CO}_{2}$ emissions and electricity flows between zones. In [98] there is a multiperiod disjunctive optimization model presented for planning investments in energy sector by total Net Present Value maximization. The model takes into account technical and economic aspects of power system operation and is applied to Argentina.

Most times the MILP programming is used for small, distributed generation systems such as in [99], [100]. In [101] authors used MILP model for distributed storage coordination (that can be used for: price arbitrage, active/reactive power control, profit maximization and balancing services) that maximizes storage's net profit. The review of micro-grid planning systems is made in [102].

\subsection{Model description and assumptions}

The authors, for the purpose of PEP 2050 development, designed a technical optimization model $-e$ Mix, representing the generation expansion planning in the Polish power sector. In the contrast to the economic approaches (general market equilibrium etc.) it focuses on the technical aspects of the power system operation linked with its operation costs. The model incorporates representation of every single unit in the power system and calculates the optimal energy mix to 2050 with one year interval. Single unit representation requires application of Mixed Integer Linear Programming and makes the model unique among other this kind models. It was already widely discussed not only in the energy sector (e.g. Government administration, Transmission System Operator, Distribution System Operators) but also in academic journals [5], [6], [103]-[105]. Below, only essential summary of the model assumptions is presented.

The objective function (1) represents the total costs of units construction and operation consisting of fixed costs $C F_{u, t}$ and variable costs $C V_{u, t}$. Fixed costs include construction cost with financial and fixed operation and maintenance costs. Variable costs consist of variable operation and maintenance costs and cost of fuel and $\mathrm{CO}_{2}$ emission allowances. The $e M i x$ calculates the annual financial burden for the power plants. It provides better approximation of the power sector operation, where investments are made thanks to the banks' loans 
and external funds. Such formulation enables the implementation of bank loan and interest rate that lead to more reliable results.

Index $u$ in formula (1) represents the particular power unit and $t$ stands for the year in assumed horizon. Component $P_{-} I_{u, t}$ denotes the installed power capacity of generating unit, $X_{u}$ is the binary variable that represents the unit's presence in the energy mix and $E_{u, t}$ is the real variable representing electricity generation of unit $u$ in year $t$.

subjected to:

$$
\min \sum_{u \in U}\left(\sum_{t \in T}\left(X_{u} \cdot P_{-} I_{u, t} \cdot C F_{u, t}+E_{u, t} \cdot C V_{u, t}\right)\right)
$$

$$
\begin{aligned}
\forall u \in U & X_{u}=0 \text { or } 1 \\
\forall u \in U, \forall t \in T & X_{u}=1 \Rightarrow E_{u, t}>0 \\
\forall u \in U, \forall t \in T & X_{u}=0 \Rightarrow E_{u, t}=0
\end{aligned}
$$

Formula (2) defines the binary variables. When $X_{u}$ equals " 0 " it means that unit $u$ does not exist in the mix, when it equals " 1 " the unit is constructed and is able to operate. More detailed formulation of binary variables is presented in [106]. Equations (3)-(4) present the relation between binary and continues variables. They denote that power unit can only produce energy if it exists in the power system in particular year $t$.

Main constraints of optimization model are presented in equations (5)-(7).

$$
\begin{gathered}
\forall t \in T \sum_{u \in U} P_{-} A_{u, t} \geq P_{-} D_{t}+K_{-} P R E S E R V E_{t} \cdot P_{-} D_{t} \\
\forall t \in T \quad \sum_{u \in U} E_{u, t}=E_{-} D_{t}
\end{gathered}
$$

Unlike majority of existing models, eMix optimizes both power and energy balance that are defined exogenously. (5) represents that in each year $t$ total available power of generating units $P_{-} A_{u, t}$ (it is usually lower than installed power) has to cover the prospective annual peak load $P_{-} D_{t}$ with required power reserve (usually $18 \%$ of average annual demand). Formula (6) presents the energy balance where total electricity generation in each year has to be equal to planned energy demand $E_{-} D_{t}$. The assumed values of power and energy demand in long-term perspective are presented in Table 7. According to the peak load, the authors decided to follow the prognosis prepared by the Department of Strategic Analyses of Chancellery of the Prime Minister of Poland [22] presented in Figure 8.

The electricity generation from particular unit has to be between minimal and maximal level (7). In $e$ Mix, the upper limit $E \_M A X_{u, t}$ results from technical parameters of unit $u$. The minimal electricity generation $E_{-} M I N_{u, t}$ means the volume of energy that has to be generated and sold to cover the fixed costs of the unit.

$$
\forall u \in U, \forall t \in T \quad E_{-} M I N_{u, t} \leq E_{u, t} \leq E_{-} M A X_{u, t}
$$

eMix includes the large power units (CDGUs), RES and nCDGUs (CHP and industrial plants) with their typical technical and financial parameters (database of type series). The CDGUs are implemented as individual units using MILP, while RES are optimized linearly considered as a group of units that is brought together according to technology.

\section{Scenarios for the energy mix development for Poland}

Scenarios analysis, which part is presented in the manuscript, is included in part "e" of the PEP 2050: (e) Perspective View for the Polish Energy Sector in 2050 - conclusions from the simulation analyses. It presents the case study carried out for the Polish power system to estimate the prospective energy mix up to 2050. The calculations were carried out using eMix optimization model and results constituted a basis for the assumed final scenarios of Polish energy mix development (see Section 4.4). 


\subsection{Calculation scenarios}

Authors upon request of Ministry of Economy, calculated dozens of simulation scenarios in order to verify the impact of particular decisions and external requirements to the final energy mix. In the manuscript, the authors' selection of the scenarios is presented as the most valuable and interesting. The scenarios differ in the aspects that highly influence the prospective shape of the power system in Poland, i.e. European Emission Allowances (EUA) price, the required level of the electricity generation from RES and the construction of the first Polish nuclear power plant according to Polish Nuclear Power Program see Section Error! Reference source not found.). As the future of the Polish power system also depends on the gas price, Table 8 presents the assumed gas price $\left(350 \$ / 1000 \mathrm{~m}^{3}\right)$ that is equal for all scenarios. It is higher than current price (see Section 2.2.2.3), but the uncertainty of a gas prices and their dependence on the political decisions do not provide reasons for very low estimations for prices. Especially, that prices for Poland in last decades was the highest in Europe. Moreover, the scenarios differ in the implementation of the learning rates for the RES.

Reference scenario is S1. It assumes the increase in the EUA price starting from $15 € / \mathrm{tCO}_{2}$ in 2020 to $40 € / \mathrm{tCO}_{2}$ in 2050. Although the current price of $\mathrm{CO}_{2}$ emissions allowances is around $9 € / \mathrm{tCO}$, such an increase is highly expected due to regulations overtaken in the EU ETS, especially introduction of the market stability reserve (MSR) [108]. The RES requirement is kept at the 19\% of the total electricity generation. It is a transformation of the EU requirement of $15 \%$ share of RES (for Poland) in total energy consumption to the requirements for RES share in electricity consumption.

S2 assumes the implementation of the Polish Nuclear Power Program, i.e. the construction of 4x1600 MW nuclear power plant with a 2-year interval between each unit, beginning from 2029. It is considered as the political decision. The scenario S3 introduces ultra-high $\mathrm{CO}_{2}$ emission allowances prices growing up to $90 € / \mathrm{tCO}_{2}$. Verification of the energy mix with high RES share is made within scenario S4. It assumes the linear growth of the minimal share of RES penetration starting from 19\% in 2020, then $27 \%$ in 2030 (EU Energy Policy 2030) and 50\% in 2050.

To address the increasing expansion of the RES in the global power systems, the scenarios S5 and S6 have been introduced. They assume the prospective development of the technology that will lead to the cost reduction of the RES in the presented time horizon. The S5 and S6 introduce the learning rates for the RES that represent the decreasing construction cost. In S5, the input parameters are assumed as in reference scenario, while the S6 represents high EUA price as in S3. Additionally, in the S5 and S6 there is no requirement for the minimum RES electricity generation and the PV potential is unlimited.

\subsection{RES potentials and learning rates}

The important input parameter that determines the maximum capacity of particular technology is the capacity potential. The value of this parameter is strictly related to the modelled power system and is particularly important for the RES development. It depends on the legal regulations (e.g. Polish law that imposes the minimum distance requirement between new wind turbines and buildings or natural protected sites) and the geographical location of the country that defines the wind speed or the sunlight exposure. In eMix the assumed potentials for the RES in Polish power system are presented in Table 9. Moreover, the presented model imposes the maximum, annual amount of the capacity for particular technology that can be commissioned in one year. This parameter is the result of the economic and technical constraints, e.g. the investors capital capacity for new investments or the restrictions to integrate new power units to the grid. The only way to implement such a limitation is direct cap put on the power capacity potential and its allowable annual increase.

Table 9 also presents the learning rates for the RES that denote the annual, relative decrease of the construction cost. The value of this parameter has been assumed according to [22] for PV, wind turbines and biogas units.

\subsection{Results of optimal energy mix}

The presented simulation results cover: installed power capacities: Figure 14-Figure 19, electricity generation: Figure 20-Figure 25, $\mathrm{CO}_{2}$ emissions: Figure 26, primary fuel consumption: Figure 27, Figure 28 total cost of electricity generation: Figure 29, Figure 30 and marginal cost for electricity generation: Figure 31. 
In all scenarios, the beginning of the optimization horizon is determined by the existing (before 2020) structure of the Polish power system. Therefore, the starting point for the optimization is high coal based power system with the $25 \mathrm{GW}$ power capacity installed in this type of technology. However, the capacity of lignite and hard coal units in all scenarios is decreasing over the years and reach $5.5 \mathrm{GW}$ in 2050.

In S1, after decommissioning of majority of coal-fired units, the dominant technology the gas become. Due to increase in the EUA price, the capacity of gas-fired power units reach $33 \mathrm{GW}$ that is over a half of total installed power in the system. Among the RES, the largest share belongs to wind turbines, as it is the least expensive RES technology. Wind onshore units reach their maximum capacity limit (16 GW) in 2035. In consequence, the second least expensive RES technology is developed - PV. It is worth to be noticed, that there are no learning rates for RES in S1. Therefore, the only reason, for which RES enter the mix, are the external requirements coming from policy options. RES themselves are too expensive in comparison to other conventional technologies. The installed power in S2 corresponds to this in the S1 but the construction of nuclear power plants (derived from the political decisions) causes the downturn in expansion of new gas-fired units. The high EUA price, as in S3, changes the installed power in the system dramatically. At the beginning of the optimized period over $6 \mathrm{GW}$ of gas-fired capacity is constructed. The nuclear power units do not appear in the power system, until the EUA price is very high. According the results obtained within the eMix, EUA must cost around 80-90 €/tCO 2 to justify investment in nuclear technology. It is caused by very high overnight costs and high costs of the capital with long construction period (Scenario S3). Despite high $\mathrm{CO}_{2}$ emission allowances price, the RES still enter the mix only to fulfill the energy policy requirements. Scenario S4 presents how the Polish energy mix would look like in case of high share of renewables. The structure of RES is diversified and the order of technologies entering the mix depend on overall costs of electricity generation. The reason why more expensive technologies appear, instead of the least expensive, is the hosting capacity of the national power system to accommodate particular technology and renewable energy resources that are implemented in the model. It can be seen that wind onshore and PV units reach their maximum potential of $16 \mathrm{GW}$.

The scenarios S5 and S6 represent the energy mix with learning curves for the RES that decrease their construction cost (see 4.2). It should be noticed that these scenarios do not include the forced requirement for RES electricity generation. Therefore, the commissioning of each unit in the system (including RES) is the result of cost minimization. Moreover, the authors decided to remove the cap for the PV technology when the limits for other RES are maintained at the same level as in S1-S4. In S5 the input parameters are as in reference scenario. Therefore, the installed capacity of conventional power plants is at similar level as in S1. The difference can be seen in the RES capacity that in S5 is even lower than in S1. The only technology among RES that is cost effective is wind onshore but it reaches its cap of $16 \mathrm{GW}$ after 2040. The decreasing construction costs of PV and biomass units do not make these technologies profitable. The situation is different in S6, where the high EUA price causes the large development of RES. The wind onshore reaches its cap in 2025 and is kept at this level to the end of the time line. After 2035 the large development of PV units is observed. The total capacity of PV reaches the level of $30 \mathrm{GW}$ in 2050.

Figure 20 - Figure 25 present the electricity generation among scenarios as a percent of a total electricity generation. The red line denotes the assumed annual energy demand that increases annually by $0.9 \%$. The results of scenarios S1, S2, S4 and S5 show that before 2030 there is a sharp drop in the energy production from coal technologies caused by the increase of EAU price. According to obtained results, if price is higher than $40 € / \mathrm{tCO}_{2}$, the gas-fired units are more competitive than coal-fired ones, even for the baseload operation, regardless the high variable costs. In scenario S2, the introduction of nuclear power units denotes a decrease in the electricity generation from gas units because of lower variable cost of nuclear technology than the other conventional units. In scenarios S3 and S6, from the very beginning the energy production from gas units is high and reach almost $20 \%$ of total electricity generation. The expansion of nuclear power units causes that in 2050 almost $40 \%$ of energy is produced by these units. In scenarios S1-S4, the energy production from RES is not higher than required levels but in S5 it is the lowest among all scenarios. In S5 the share of RES in total electricity generation is lower than $10 \%$ before 2030 . Then it grows to about $15 \%$ in 2050 . It is a result of the lack of the minimum requirement of RES electricity generation. Only wind onshore technology is commissioned even though the construction costs of other RES are decreasing with time. The S6 shows that the other RES technologies are cost effective when there is a high EUA price. The large development of PV units after 2035 causes that the share of the RES equals over $30 \%$. 
Figure 26 presents that every scenario results with a decrease in the $\mathrm{CO}_{2}$ emissions. In almost every scenario the imposed requirement by EU of $43 \% \mathrm{CO}_{2}$ emissions reduction after 2030 is fulfilled (in Poland it means $40 \%$ in ETS sector in comparison do 2005 and the emissions below 103 million $\mathrm{tCO}_{2}$ ). Surprising is the fact that the highest emissions occur in scenario S4 (high RES share). This situation is due to large share of biomass technology in the total electricity generation. Depending on approach, emissions from biomass are not considered in carbon dioxide final balance, however emissions during burning the wood pellets occur. The lowest $\mathrm{CO}_{2}$ emissions are in scenario S6 where there is a large development of both nuclear power units and carbon-free RES technologies (wind onshore and PV).

The primary fuel consumption presented in Figure 27 and Figure 28 shows the gradual switch from the lignite and hard coal consumption to the gas. The gas use only for electricity generation in S1 or S5 equals 4345 billion $\mathrm{m}^{3}$, what stands for a great challenge for the Polish economy to ensure such a large gas volumes, which in majority has to be imported. However, commissioning of nuclear power units as in S2, S3 and S6 denotes the gas consumption at the level of 13-25 billion $\mathrm{m}^{3}$. The similar effect is triggered in $\mathrm{S} 4$ by the high development of renewables. Execution of any scenario will required large effort for the economy to adjust associated sectors especially for providing new sources for the gas import, strengthening the gas transmission system, increasing liquidity of a gas market and establishing the base for the nuclear industry, which in Poland does not exist.

The structure of total costs of the power system divided into: financial, fixed and variable O\&M, fuel and $\mathrm{CO} 2$ emissions allowances costs is presented in Figure 29 and Figure 30.

The need for the new investments in the Polish power system causes the capital and financial cost of almost every scenario is increasing. Only in S5 the financial cost slightly decreases after 2040. In S1, with high investments in gas-fired units, the main costs' component is the fuel. In other scenarios, the financial cost dominates, due to a construction of nuclear power plants or renewables with high CAPEX. The impact of the high $\mathrm{CO}_{2}$ prices on the total costs in the power system is highly evident in S3 and S6 in 2020. To mitigate this impact in the following years, the structure of the power system has changed to low-emissive technologies.

Finally, the marginal cost for electricity generation (Figure 31) presents the possible impact on the energy prices for the energy consumers. Due to transformation needs towards more sustainable energy mix, every development scenario is associated with increased marginal cost of electricity. In the long-term perspective, prices at the markets converge to the costs of production. Hence, electricity price for the final consumers will go up in the future. Electricity sector must be transformed and it cannot be achieved at current costs.

\subsection{Final 2050 Policy Scenarios for Poland}

The final shape of the energy policy for Poland will depend on administration and government actions. On the basis of results presented, final shape of the energy policy (actual for the April 2016) were developed and scenarios for energy mix were assumed. Policy makers must take into account the following issues:

- The pursuit of constraining the negative impact of energy sector on environment

- Already accepted European Union policies that concern particular elements of energetic sectors

- Current state of discussion on the further development of situation in particular areas of power system in Poland that involve:

$\circ \quad$ The costs and range of using the domestic supplies of hard coal and lignite

- Possible development of nuclear energy sector in Poland

- Potential of unconventional gas supplies extraction

- Potential of unconventional energy sources

Energy policy assumes three competitive scenarios for the energy mix development. The first one is a reference scenario that assumes that the current trends in energy sector will remain the same. The next two scenarios are auxiliary scenarios and constitute analytical variants. The auxiliary scenarios are embedded on the existing structure of generating assets and its probable change.

\subsubsection{Common assumptions}

For all scenarios it is assumed, that the transmission and distribution grid will expand. In 2050 perspective, all grids will be the smart-grids. As a result of implementation of internal energy market in Europe, the interconnections will be strongly developed - their capacity will constitute a significant percentage of capacity in- 
stalled in the system. After 2035, the subsidizing for RES will be withdrawn and those technologies will have to be able to achieve economical independency. The Program of Polish Nuclear Energy in the accepted shape will be realized. Each of the scenarios assumes the continual increase of energy efficiency be it the efficiency of energy sector or heating, housing and final use of energy. The energy market will also change drastically. Those changes will result from:

- The increase in number of prosumers (mostly those with micro generation) - their expansion will be facilitated thanks to the limited restrictions related to the integration with distribution lines

- Incentivizing the DSR - the industrial consumers will be providing their DSR services for operators directly, while the household consumers through the integrators

- Rationalization of energy consumption that can be accomplished given to the Advanced Metering Infrastructure - the real-time electricity pricing will encourage the electricity recipients to become more active and responding consumers. It will be also possible to store energy in the electric vehicles.

- Increasing flexibility and diversification of offers of electricity sellers that will be having access to the data from abovementioned meters. It is expected to introduce the possibility of demand reduction and prepaid offers that would be functioning similarly to the pay-as-you-go mobile offers.

\subsubsection{Sustainable scenario}

This scenario is a most probable scenario and is very close to the calculated within the eMix S2 scenario.

In the sustainable scenario, the Polish energy balance in 2050 will be comparable to the one established in 2035. This scenario also assumes the maintenance of the significant (however limited in comparison to present situation) role of coal and crude oil and a moderate growth of importance of natural gas. The RES will expand their share in the energy mix. It would among other things result from:

- European energy policy that assumes the $10 \%$ of RES share in production of transport fuels and $15 \%$ in primary energy balance (up to 2020)

- Targets concerning reductions of $\mathrm{CO}_{2}$ emissions

- Construction of two nuclear generating units of total $6400 \mathrm{MW}$ that would constitute $12 \%$ of primary energy.

The RES expansion could be nevertheless more profound that it has been predicted. EU and global resolutions on environmental issues are very important stimuli, and their precise impact hard to predict. The sustainable scenario assumes:

- The sustainable extraction of solid fuels including extraction of new deposits at the lowest possible costs but with regard to future generations' needs. The mining sector must undergo a change that will increase its productivity. This can be achieved through reorganization of the existing assets and alternatively through the development of new technologies of mining. Because the already being exploited deposits are becoming exhausted or more and more problematic to make use of, some new mines will have to be created.

- Realization of nuclear energy plan. Polish nuclear energy sector needs specialized staff and investments in the research and development branch.

- Realization of subsidizing plan for RES and cogeneration as well as development of prosumers sector and micro-generation.

- Increase of the share of gas in energy production. This target can be accomplished through: education of the staff that would coordinate the LNG terminal, subsidizing the use of natural gas in transport and doing researches on the shale gas extraction.

- Increasing the energy efficiency of economy (industry and final consumers).

- Investment in new conventional power plants that would take advantage on domestic natural supplies. The share of coal in energy production should be followed by the development of clean coal technology.

This scenario allows for fulfillment of European Energy Policy goals as for the reduction of greenhouse gases emission thanks to the increase in share of RES, implementing the nuclear power plant, increase of the energy efficiency of energy production, transmission and use and the use of clean coal technology.

\subsubsection{Alternative nuclear scenario}

The nuclear scenario assumes the expansion of nuclear power energy that would constitute up to $60 \%$ of total energy produced. This scenario involves huge long-term investment on the realization of nuclear plan, but 
those expenses could be compensated by the low nuclear fuel prices, independence from liquid fuel imports and the reduction of costs resulted from the need of buying $\mathrm{CO} 2$ emission allowances.

The share of particular technologies in energy production is predicted to be as follows: nuclear energy 40 $60 \%$, hard coil and lignite $10-15 \%$, crude oil 10-15\%, natural gas $10-15 \%$ and RES $15 \%$. The scenario requires the construction of more than one nuclear power plants. Their allocation should be profoundly considered and take into account the allocation of conventional units. The growth in electricity production from uranium will result in the reduction of use of liquid fuels in transportation and the extraction of coal. The RES will be limited to the distributed micro-generation for prosumers purposes.

\subsubsection{Alternative gas + RES scenario}

The gas+RES scenario assumes the combined share of those two technologies to reach $50-55 \%$ in 2050 . Those two technologies complement one another, since gas units are flexible units and can be launched in short notice when the intermittent generation does not produce. The share of particular technologies in energy production is predicted to be as follows: gas+RES 50-55\% (at least 20\% of RES), hard coal and lignite 15$20 \%$, nuclear $12 \%$.

The gas supplies would be extracted from conventional and unconventional deposits in Poland, but also from LNG terminal, Yamal pipeline and interconnectors. The growing share of gas fueling in transportation would also limit the dependence on imported crude oil. Gas would also become more popular among individual consumers - both households and industries. This scenario requires further development of gas transportation infrastructure and storage systems since the demand for the gas increase sharply in the winter periods.

\section{Conclusions and Policy Implications}

The paper analyses the situation of the Polish energy sector - underinvested and coal-based - which has to face EU energy and climate policy and undergo a transformation to more sustainable and diversified one in a very short time. Policy makers in Poland, being aware of the challenges, started to implement actions towards energy sector and especially power system reforms and the effect of those actions is proposal of the Polish Energy Policy 2050, described in the paper. Authors of the manuscript had an opportunity to support a development of the policy as the part of advisory board, being responsible for the modelling and analyzing the impact of various assumptions for the future energy mix in Poland. Decisions about the final policy assumptions are left to the politicians.

In the manuscript, authors presented selected scenarios for the Polish energy mix transformation, driven by the assumed decisions concerning the sector, fulfilling the ideas of EU energy and climate policy - mainly decarbonizing. Generally, scenarios can be divided into two groups: without any learning rates and with learning rates for the RES. Moreover, the scenarios with learning rates for renewables include no limit for PV potential that can be found as a technology with high possibilities to develop in the Polish power system. According to the obtained results, the highest reduction in $\mathrm{CO}_{2}$ emissions provides energy mix based on nuclear power plants. The lower decrease in emissions provides scenario with high share of renewables without any learning rates. It is a result of the potentials imposed on the RES technologies. When carbon-free technologies (mainly wind turbines and PV) reach their capacity limit, the biomass and biogas units are commissioned. While the nuclear investments are activated by the very high price of EUA $\left(90 € / \mathrm{tCO}_{2}\right)$, the highest cost of the electricity production occurs in energy mix with high share of renewables without any learning rates. It shows that investing in renewables with current capital costs and limited potential of particular technologies is although environmental friendly, also the most expensive and provides the least reduction of $\mathrm{CO}_{2}$ emissions. However, the scenario with high EUA price and learning rates for RES shows that the decrease in the capital costs of RES and increase of PV potential will give the lowest $\mathrm{CO}_{2}$ emissions among all scenarios. It indicates that in future, and with some additional measures (high EUA prices) RES units may become fully competitive to the conventional electricity sources. In fact, assuming subsidies for RES it could be earlier that results indicates, as the optimization model does not consider subsidies, but only pure investment costs (with credits). All of this alternative scenarios are very dangerous for Polish economy, because of being most expensive. In addition, they would require high expenditures in the electricity sector up to $€ 20-25$ billion annually in 2050 and would result in growth of electricity prices above $100 € / \mathrm{MWh}$. BAU scenario, assuming aligning with the EU policy at the least costs is a very interesting scenario. Assuming the EUA prices at $40 € / \mathrm{COO}_{2}$, this scenario provides over $30 \%$ reduction in $\mathrm{CO}_{2}$ emissions in 2030 in comparison to 2020, and keeps the electricity prices below $80 € / \mathrm{MWh}$. Nevertheless, this scenario would require switching the power sector to gas, which taking into account the unpredictable gas supply and its prices is very risky. Additionally, 
this scenario would require expansion of the gas transmission system and searching for new gas suppliers, as a gas consumption only for power sector would grow from $1 \mathrm{mld} \mathrm{m}^{3}$ (2020), $26 \mathrm{mld} \mathrm{m}^{3}$ (2030) to $46 \mathrm{~m}^{3}$ (2050). It can be achieved observing continuous development of LNG infrastructure and gas market in Europe.

Results of the analysis summarized above are reasonable and clearly indicate, that it is not possible to integrate all the possible technologies in the Polish power sector. As the current basis is coal and lignite technology, any other will require not only the investments in power plants but also investments in the auxiliary subsectors dedicated to them. For example, switching to gas - investments in gas infrastructure, switching to nuclear - development of the entire nuclear industry as Poland never used this technology. Providing the high penetration of RES would require back-up capacities, grid extensions and maybe development of own technologies to prevent from transfer all funds abroad to the technologies suppliers. Therefore, it is highly important to indicate the path, which Poland would follow in the future. This path must be clear, stable and fully supported by the government to provide good framework for the operation for the sector's actors.

Unfortunately, proposal of Polish Energy Policy 2050 does not fulfil described requirements. PEP 2050 only briefly diagnoses the problems of energy sector in Poland but does not provide any solutions. It does not define the clear path for development and transformation, which could be used for construction of adequate mechanisms and measures to achieve the objectives. Three alternate scenarios described in the proposal of policy are only hypothetical and the policy is not followed by any important decisions. In the policy it is even stated "the future shape of the energy mix is dependent on the decisions that were already made", what means that at the moment there is no clear plan for the future of Polish energy sector transformation. Moreover, the Execution Plan, being a part of a policy, do not enter the long-term perspective and focuses only on the three following years. It does not indicate any tools or mechanisms that should be incorporate to support the energy sector operation.

Policy does not investigate:

a. any actions towards new market design, suitable for the RES and conventional units,

b. actions towards secure and predictable operation of electricity interconnectors to suppress the loop flows and transit flows,

c. problems relating the prosumers development,

d. innovative approach to local energy balancing, increasing the responsibility of Distribution System Operator s in power system balancing,

e. opportunities to use the energy sector as a leverage for the economic growth and increase of the GDP,

f. Supporting the national technologies for electricity generation (RES and conventional) and preventing from transferring all expenditures to foreign manufacturers,

g. Social problems, connected with very large mining industry, which would not be needed if Poland leave the electricity generation based on coal,

h. High prices of electricity that is extremely dangerous for energy intensive industries.

Polish energy sector based on inefficient usage of coal must be transformed according to the requirements of EU energy and climate policy. Nonetheless, strong attachment to the coal causes that transformation cannot be achieved overnight and requires a series of responsible decisions. Development of these decisions should involve multidisciplinary analyses indicating not the least expensive and the easiest solutions but those which will have the best impact on the entire economy.

\section{Acknowledgements}

The authors would like to thank the Department of Energy at the Ministry of Economy for invaluable remarks from perspective of government administration and policy makers during process of development of Polish Energy Policy 2050.

The authors would like to express the gratitude to the FICO® corporation for programming support and provision of academic licenses for Xpress Optimization Suite to Institute of Electrical Power Engineering at Lodz University of Technology.

The authors would like to thank Prof. Wladysław Mielczarski, also involved in the consultation of the Energy Policy 2050 for Poland, for his supervisory and the paper review. 
The authors would like to thank the Lodz University of Technology Computer Center as the calculations mentioned in this paper were performed using the PLATON project's infrastructure.

\section{References}

[1] The World Bank, "World Development Indicators," World Bank national accounts data, and OECD National Accounts data files, 2016. [Online]. Available: http://databank.worldbank.org/data/reports.aspx?source=2\&series=NY.GDP.MKTP.KD.ZG\&country =\#. [Accessed: 21-Oct-2016].

[2] Moody's, "Rating Action : Moody's affirms Poland's A2 / P-1 government bond ratings with stable outlook," 2015. [Online]. Available: https://www.moodys.com/research/Moodys-affirms-PolandsA2P-1-government-bond-ratings-with-stable--PR_324910. [Accessed: 21-Oct-2016].

[3] H. Foy, "Polish manufacturers hit by power cuts," Financial Times, Warsaw, 2015.

[4] TGE (Polish Power Exchange), At the heart of Central European power and gas trading. 2016.

[5] M. Wierzbowski, W. Lyzwa, and I. Musial, "MILP model for long-term energy mix planning with consideration of power system reserves," Appl. Energy, vol. 169, pp. 93-111, 2016.

[6] W. Lyzwa, M. Wierzbowski, and B. Olek, "MILP Formulation for Energy Mix Optimization," IEEE Transactions on Industrial Informatics, vol. 11, no. 5. pp. 1166-1178, 2015.

[7] Eurostat, "Supply, transformation and consumption of electricity - annual data [nrg_105a]," 2016. [Online]. Available: http://appsso.eurostat.ec.europa.eu/nui/submitViewTableAction.do. [Accessed: 23-Oct-2016].

[8] Eurostat, "Energy production and imports," 2016. .

[9] European Commission, "European Energy Security Strategy," European Commission Website. p. 24, 2014.

[10] Council of the European Union, “Council directive 2009/119/EC.” pp. 9-23, 2009.

[11] European Commission, "A policy framework for climate and energy in the period from 2020 to 2030." Brussels, 2014.

[12] RWE, "Report on energy market in 2014 (in Polish)," 2015. .

[13] PSE S.A. (Polish Transmission System Operator), "2014 Polish Energy System operation data (in Polish)," 2015. [Online]. Available: http://www.pse.pl/index.php?did=2232\#t2_1. [Accessed: 13-Jan2016].

[14] ENTSO-E, "Electricity in Europe 2014,” Brussels, 2014.

[15] WNP.PL, "Electricity import two times higher than previous year (in Polish)," 2014. [Online]. Available: http://energetyka.wnp.pl/import-energii-blisko-dwa-razy-wiekszy-niz-roktemu,238916_1_0_0.html. [Accessed: 13-Jan-2016].

[16] PSE S.A. (Polish Transmission System Operator), "2013 Polish Energy System operation data (in Polish)," 2014. [Online]. Available: http://www.pse.pl/index.php?did=1717\#top. [Accessed: 13-Jan2016].

[17] PSE S.A. (Polish Transmission System Operator), "Yearly power balance 2014 (in Polish)," 2015.

[18] The Chancellery of the Prime Minister, "Long-term financial plan of Poland 2016 - 2019 (in Polish)." Warsaw, 2016.

[19] L. Gawlik, Coal for Polish Power Sector 2050 (in Polish). Katowice: GIPH, 2013.

[20] European Commission, "EU Energy, Transport and GHG Emissions: Trends to 2050 - Reference Scenario 2013.” p. 173, 2013.

[21] Polish Ministry of Economy, "Prognosis analysis for Polish Energy Policy 2050 (in Polish)." 2015.

[22] Department for Strategic Analyses. Chancellery of the Prime Minister of the Republic of Poland, "Optimal energy mix for Poland until 2060 (in Polish)," Warsaw, 2015.

[23] ARE S.A. (The Energy Market Agency), "Statistics of Polish Power System (in Polish)," 2014.

[24] Polish Ministry of Economy, “co.” 2014.

[25] Polish Information and Foreign Investment Agency, "Energy Sector in Poland," 2015.

[26] Supreme Audit Office. Republic of Poland., "Conventional power generation adequacy. Control report /P/14/018/KGP. (in Polish)," Warsaw.

[27] PSE S.A. (Polish Transmission System Operator), "Yearly Coordination plan 2016," 2016. [Online]. Available: http://www.pse.pl/index.php?modul=10\&gid=479. [Accessed: 20-Sep-2016].

[28] Ministry of Economy Republic of Poland, "REPORT ON THE RESULTS OF MONITORING OF 
SECURITY OF ELECTRICITY SUPPLY," Warsaw, 2015.

[29] PSE S.A. (Polish Transmission System Operator), "PSE's comment on publication of FAE regarding power outages in Polish Energy Sector in August 2015 (in Polish)." 2015.

[30] PSE S.A. (Polish Transmission System Operator), "Polish Power System Data and Reports," Data and Reports on Polish Power System. [Online]. Available: www.pse.pl.

[31] World Economic Forum, "Global Energy Architecture Performance Index Report 2015,” 2014.

[32] ENTSOE, "Winter outlook 2015/2016 \& summer rwview," 2015.

[33] PSE S.A. (Polish Transmission System Operator), "Information about power sytstem (in Polish)," 2016. .

[34] Supreme Audit Office. Republic of Poland., "Functioning and security of transmission network in Poland. Control report 27/2014/P/13/055/KGP (in Polish)," 2014.

[35] Natonal Security Bureau, "Raport on security of electricity transmisson system in Poland (in Polish)," 2008.

[36] M. Ruszel, "Polish transmission system security (in Polish)," Rzeszow, 2013.

[37] National Security Bureau, "Electricity transmission loses analysis (in Polih)," 2012.

[38] Biznesalert.pl, "New interconnection between Lithuania, Poland and Sweaden creates Baltic Ring (in Polish)," 2015. .

[39] European Commission, "Electricity interconnection Sweden - Lithuania (Nordbalt - 01)," 2013.

[40] H. Majchrzak, "Electricity transmission griddevelopment under Internal Energy Market," 2013.

[41] K. Purchała, "The biggest challenges in creating Internal Energy Market (in Polish)," 2015.

[42] British Petroleum, "BP Statistical Review of World Energy June 2015," no. June, p. 48, 2015.

[43] Eurostat, "Simplified energy balances - annual," 2015. [Online]. Available: http://appsso.eurostat.ec.europa.eu/nui/submitViewTableAction.do.

[44] T. Donald, J. K. Pitman, R. R. Charpentier, T. Cook, T. R. Klett, and C. J. Schenk, "Potential for Technically Recoverable Unconventional Gas and Oil Resources in the Polish-Ukrainian Foredeep, Poland, 2012," no. July, 2012.

[45] M. Strzelecki, "Poland Says Shale Reserves May Be 85\% Below U.S. Estimate," 2012. [Online]. Available: http://www.bloomberg.com/news/articles/2012-03-21/poland-may-have-768-billion-cubicmeters-shale-gas-reserves-1-. [Accessed: 20-Jan-2016].

[46] EIA (Energy Information Administration), "Technically Recoverable Shale Oil and Shale Gas Resources: An Assessment of 137 Shale Formations in 41 Countries Outside the United States," 2013.

[47] N. Buckley, "Eastern European shale exploration on ice as boom turns to bust," Financial Times, 2015.

[48] N. Butler, "Shale - the unfinished revolution," Financial Times, 2015.

[49] PAP, "European Commission strive for equal prices in European Union (in Polish)," 2016. [Online]. Available: http://gazownictwo.wnp.pl/ke-chce-dazyc-do-wyrownywania-cen-gazu-wue,267179_1_0_0.html. [Accessed: 11-Feb-2016].

[50] A. Kublik, "Russia announced the gas price for Poland and Ukraine (in Polish)," wyborcza.biz, 2015. [Online]. Available: http://wyborcza.biz/biznes/1,100896,18914152,rosja-oglosila-cene-gazu-dlaukrainy-i-dla-polski.html. [Accessed: 01-Jan-2016].

[51] G. Lys, "The problem is not enymore the lack, but the price of gas (in Polish)," Forbes, 2015. .

[52] PGNiG, "Storage," 2015. [Online]. Available: http://en.pgnig.pl/segments-of-activity/trade-andstorage/storage. [Accessed: 11-Feb-2016].

[53] World Energy Council, "Energy sector of the world and Poland," Warsaw, 2014

[54] Biznesalert.pl, "APR: in 2015 polish mines sold more than extracted (in Polish)," 2016. [Online]. Available: $\quad$ http://biznesalert.pl/arp-w-2015-r-kopalnie-sprzedaly-wiecej-wegla-niz-wydobyly/. [Accessed: 19-Feb-2016].

[55] PAP, "In 2015 polish mines sold more coal than extracted (in Polish)," 2016. [Online]. Available: http://wyborcza.pl/1,91446,19597440,w-2015-r-kopalnie-sprzedaly-wiecej-wegla-niz-wydobyly.html. [Accessed: 19-Feb-2016].

[56] A. Gaweda, "Current situation od hard coal sector (in Polish)," Zesz. Nauk. Inst. Gospod. Surowcami Miner. i Energia PAN, no. 87, pp. 5-24, 2014.

[57] J. Piszczatowska, "7 sins of Polish mining (in Polish)," wysokienapiecie.pl, 2014. [Online]. Available: http://wysokienapiecie.pl/energetyka-konwencjonalna/371-7-grzechow-polskiego-gornictwa.

[Accessed: 18-Feb-2015]. 
[58] WNP.PL, "Coal prices," 2016. .

[59] cire.pl, "ARP Analysis: coal market still in deep recession (in Polish)," 2016. [Online]. Available: http://www.cire.pl/item,124959,1,0,0,0,0,0,analiza-arp-rynek-wegla-nadal-w-glebokiej-recesji.html. [Accessed: 19-Feb-2016].

[60] Energy Regulatory Office, "Capacity installed in RES as of 31.12.2014 (in Polish)," 2015.

[61] Energy Regulatory Office, "Electricity generated by RES as of 31.12.2014 (in Polish),” p. 2015, 2015.

[62] M. Jasiulewicz, "The energety potential of agriculture biomass in Polish regions in the aspect of the realize national aim index at the RES 2020 year (in Polish)," Rocz. Nauk., vol. XVI, no. 1, pp. 70-76, 2008.

[63] Development Initiatives Forum, “Analysis: Polish power (in)dependence (in Polish),” Bialystok, 2014.

[64] Salon24.pl, "Anti-economics and anti-ecology: energy from imported biomass (in Polish)," 2015. [Online]. Available: http://energetyka.salon24.pl/687709, antyekonomia-i-antyekologia-czyli-energiaz-importowanej-biomasy. [Accessed: 01-Mar-2015].

[65] I. Sudak, "Big problem with biomass. In Polish boilers we burn... coconuts! (in Polish)," wyborcza.biz, $2014 . \quad$ [Online]. Available: http://wyborcza.biz/biznes/1,147744,15839952,Wielki_klopot_z_biomasa_W_polskim_piecu_palim y__.html. [Accessed: 01-Mar-2016].

[66] B. Gradziuk, "Foreign Trade of Biomass for Energy Purposes in Poland in the Years 2008 - 2014," vol. 2, no. 3, 2015.

[67] G. Wisniewski, K. Michalowska-Knap, and G. Kunikowski, "Evaluation of economical aspects of further subsidizing cofiring of biomass and coal (in Polish)," Warsaw, 2013.

[68] Forbes.pl, "Polish absurd: biomass (in Polish)," 2012. .

[69] T. (Polish P. Exchange), "TGE Monthly report - March 2016," 2016.

[70] K. Zamasz, "Financial Aspects of the Capacity Market Implementation in Poland (in Polish)," Przeglad Organ., vol. 4, pp. 26-32, 2015.

[71] S. Ali-Oettinger, "Heatwave causes prices to soar in Poland's coal-dominated grid," 2015. [Online]. Available: http://www.pv-magazine.com/news/details/beitrag/heatwave-causes-prices-to-soar-inpolands-coal-dominated-grid_100020560/\#axzz41fjpGwq2. [Accessed: 01-Mar-2016].

[72] Ernst \& Young, "Raport from II phase of project: Energy security in Poland thanks to implementation of capacity remuneration mechanisms (in Polish)," 2014.

[73] TGE (Polish Power Exchange), "TGE Monthly report - January 2016,” 2016.

[74] Polish Ministry of Economy, "Polish Nuclear Power Programme." Warsaw, 2014.

[75] PAP, "When will the Polish nuclear power plant start operation? (in Polish)," gazetaprawna.pl, 2015.

[76] Aneta Wieczerzak-Krusińska, "Polish nuclear power plant in 2031? (in Polish)," rp.pl. .

[77] S. Pfenninger, A. Hawkes, and J. Keirstead, "Energy systems modeling for twenty-first century energy challenges,” Renew. Sustain. Energy Rev., vol. 33, pp. 74-86, May 2014.

[78] M. Welsch, P. Deane, M. Howells, B. Ó Gallachóir, F. Rogan, M. Bazilian, and H.-H. Rogner, "Incorporating flexibility requirements into long-term energy system models - A case study on high levels of renewable electricity penetration in Ireland," Appl. Energy, vol. 135, pp. 600-615, Dec. 2014.

[79] D. Connolly, H. Lund, B. V. Mathiesen, and M. Leahy, "A review of computer tools for analysing the integration of renewable energy into various energy systems," Appl. Energy, vol. 87, no. 4, pp. 10591082, Apr. 2010.

[80] P. Alberg Ostergaard, B. V. Mathiesen, B. Moller, and H. Lund, "A renewable energy scenario for Aalborg Municipality based on low-temperature geothermal heat, wind power and biomass," Energy, vol. 35, no. 12, pp. 4892-4901, 2010.

[81] H. Lund and B. V. Mathiesen, "Energy system analysis of $100 \%$ renewable energy systems-The case of Denmark in years 2030 and 2050," Energy, vol. 34, no. 5, pp. 524-531, 2009.

[82] D. Connolly, H. Lund, B. V. Mathiesen, and M. Leahy, "The first step towards a 100\% renewable energy-system for Ireland," Appl. Energy, vol. 88, no. 2, pp. 502-507, 2011.

[83] B. Cosic, G. Krajacic, and N. Duic, "A 100\% renewable energy system in the year 2050: The case of Macedonia," Energy, vol. 48, no. 1, pp. 80-87, 2012.

[84] G. Krajacic, N. Duic, and M. da G. Carvalho, "How to achieve a 100\% RES electricity supply for Portugal?," Appl. Energy, vol. 88, no. 2, pp. 508-517, 2011. 
[85] F. Chen, N. Duic, L. M. Alves, and M. Grac, "Renewislands - Renewable energy solutions for islands," vol. 11, pp. 1888-1902, 2007.

[86] I. G. Mason, S. C. Page, and A. G. Williamson, "A 100\% renewable electricity generation system for New Zealand utilising hydro, wind, geothermal and biomass resources," Energy Policy, vol. 38, no. 8, pp. 3973-3984, 2010.

[87] A. I. Tolis and A. A. Rentizelas, "An impact assessment of electricity and emission allowances pricing in optimised expansion planning of power sector portfolios," Appl. Energy, vol. 88, no. 11, pp. 3791-3806, Nov. 2011.

[88] A. Rentizelas and D. Georgakellos, "Incorporating life cycle external cost in optimization of the electricity generation mix," Energy Policy, vol. 65, pp. 134-149, Feb. 2014.

[89] A. C. Tahir and R. Bañares-Alcántara, "A knowledge representation model for the optimisation of electricity generation mixes,” Appl. Energy, vol. 97, pp. 77-83, 2012.

[90] D. Zhang, P. Liu, L. Ma, Z. Li, and W. Ni, "A multi-period modelling and optimization approach to the planning of China's power sector with consideration of carbon dioxide mitigation," Comput. Chem. Eng., vol. 37, pp. 227-247, Feb. 2012.

[91] A. Pina, C. A. Silva, and P. Ferrao, "High-resolution modeling framework for planning electricity systems with high penetration of renewables," Appl. Energy, vol. 112, pp. 215-223, 2013.

[92] M. A. H. Mondal, S. Kennedy, and T. Mezher, "Long-term optimization of United Arab Emirates energy future: Policy implications,” Appl. Energy, vol. 114, pp. 466-474, 2014.

[93] N. Victor, C. Nichols, and P. Balash, "The impacts of shale gas supply and climate policies on energy security: The U.S. energy system analysis based on MARKAL model," Energy Strateg. Rev., vol. 5, pp. 26-41, 2014.

[94] S. Ahmed, M. Elsholkami, A. Elkamel, J. Du, E. B. Ydstie, and P. L. Douglas, "Financial risk management for new technology integration in energy planning under uncertainty," Appl. Energy, vol. 128, pp. 75-81, Sep. 2014.

[95] C. Barteczko-Hibbert, I. Bonis, M. Binns, C. Theodoropoulos, and A. Azapagic, "A multi-period mixed-integer linear optimisation of future electricity supply considering life cycle costs and environmental impacts," Appl. Energy, vol. 133, pp. 317-334, Nov. 2014.

[96] B. Alizadeh and S. Jadid, "A dynamic model for coordination of generation and transmission expansion planning in power systems," Int. J. Electr. Power Energy Syst., vol. 65, pp. 408-418, Feb. 2015.

[97] N. E. Koltsaklis, A. S. Dagoumas, G. M. Kopanos, E. N. Pistikopoulos, and M. C. Georgiadis, "A spatial multi-period long-term energy planning model: A case study of the Greek power system," Appl. Energy, vol. 115, pp. 456-482, Feb. 2014.

[98] J. R. Flores, J. M. Montagna, and A. Vecchietti, “An optimization approach for long term investments planning in energy," Appl. Energy, vol. 122, pp. 162-178, 2014.

[99] A. Omu, R. Choudhary, and A. Boies, "Distributed energy resource system optimisation using mixed integer linear programming," Energy Policy, vol. 61, pp. 249-266, 2013.

[100] J. Silvente, G. M. Kopanos, E. N. Pistikopoulos, and A. Espuña, “A rolling horizon optimization framework for the simultaneous energy supply and demand planning in microgrids," Appl. Energy, vol. 155 , pp. $485-501,2015$.

[101] R. Moreno, R. Moreira, and G. Strbac, "A MILP model for optimising multi-service portfolios of distributed energy storage,” Appl. Energy, vol. 137, pp. 554-566, 2015.

[102] C. Gamarra and J. M. Guerrero, "Computational optimization techniques applied to microgrids planning: A review,” Renew. Sustain. Energy Rev., vol. 48, pp. 413-424, 2015.

[103] W. Lyzwa, J. Przybylski, and M. Wierzbowski, "Modeling of power reserves and RES in optimization of Polish energy mix," European Energy Market (EEM), 2015 12th International Conference on the. pp. 1-5, 2015.

[104] W. Lyzwa, M. Wierzbowski, B. Olek, F. Stuchala, and W. Mielczarski, "The impact of energy policy 2030 on the edge countries. Case study for Poland," European Energy Market (EEM), 2015 12th International Conference on the. pp. 1-5, 2015.

[105] M. Wierzbowski, "Energy mix optimisation - Case study for Poland," in European Energy Market (EEM), 2014 11th International Conference on the, 2014, pp. 1-5.

[106] W. Lyzwa, M. Wierzbowski, and B. Olek, "MILP formulation for energy mix optimization," IEEE Trans. Ind. Informatics, vol. 3203, no. c, pp. 1-1, 2015.

[107] PSE S.A. (Polish Transmission System Operator), "Prognosis of peak demand for 2016-2035 (in 
Polish), 2016.

[108] T. O. T. H. E. Point, "2030 EU Carbon Price Forecast: What' s next for the EU ETS 2030 Carbon Price Forecast Introduction," 2015.

[109] PGNiG, "Corporate Presentation Financial Results of 3Q 2014," 2015.

[110] A. Kublik, "More Russian gas from Germany to Poland. This way it will be cheaper (in Polish)," wyborcza.biz. [Online]. Available: http://wyborcza.biz/biznes/1,100896,17217194,Wiecej_rosyjskiego_gazu_z_Niemiec_do_Polski_W _ten.html.

[111] cire.pl, "Gas imports (in Polish)," 2015. [Online]. Available: http://www.rynekgazu.cire.pl/st,43,288,tr,33,0,0,0,0,0,zrodla-zaopatrzenia.html. [Accessed: 04-Feb-2016]. 


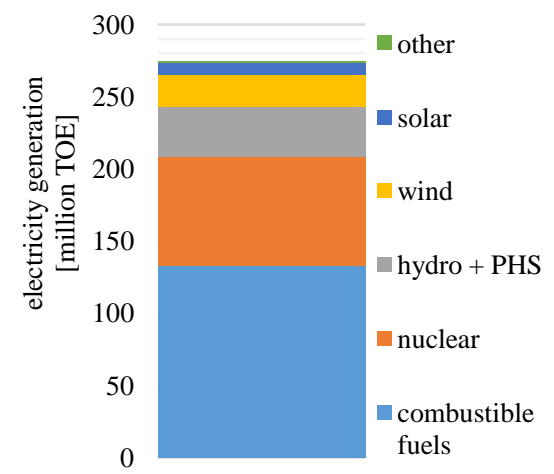

Figure 1 Gross power generation in EU-28 in 2014 [7]
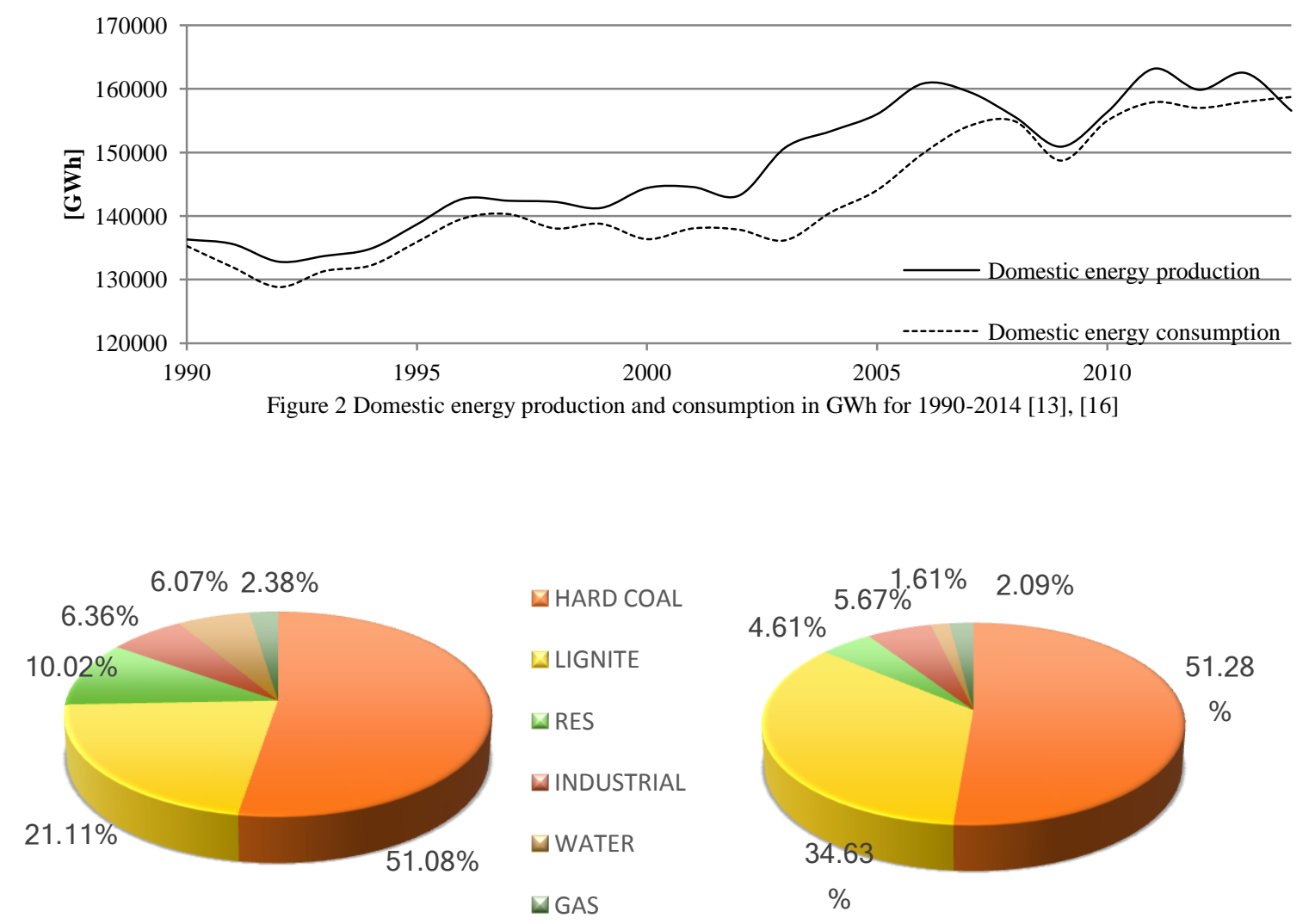

Figure 3 Capacity available in 2014 (left) and energy production (right) [13], [16] 

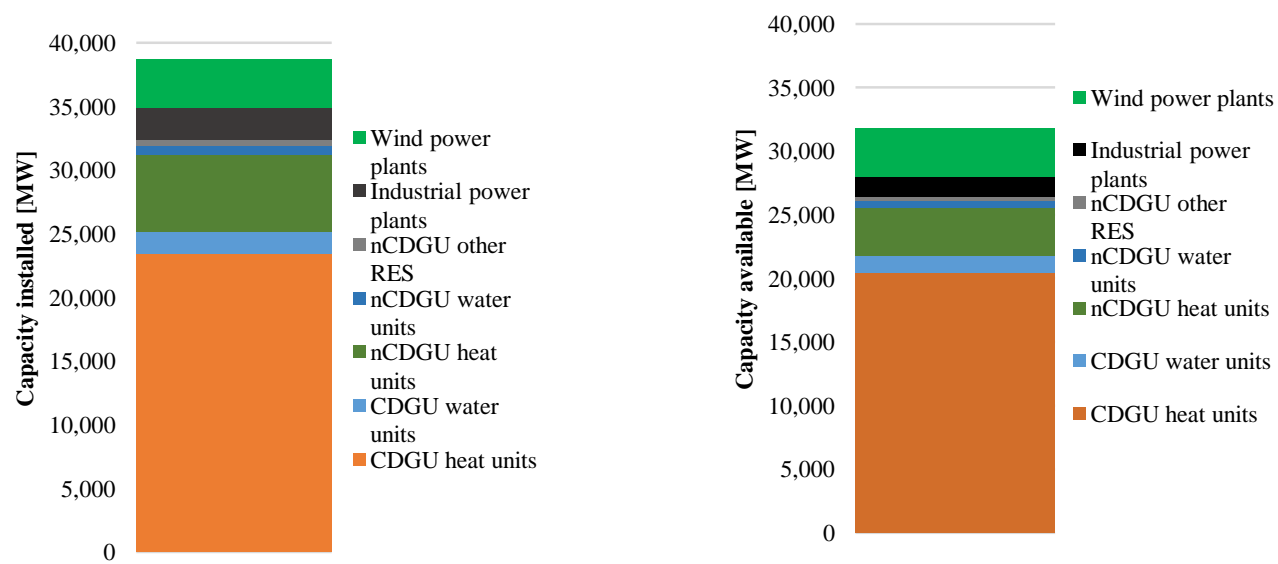

Figure 4 Capacity installed in 2014 (left) and capacity available (right). CDGU - Centrally Dispatched Generating Units, nCDGU - not Centrally Dispatched Generating Units [17]

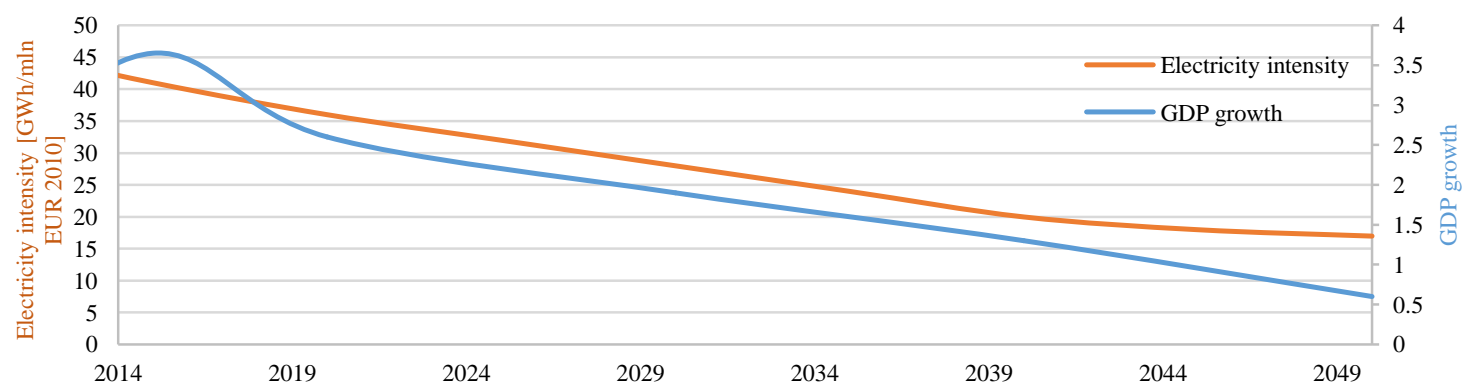

Figure 5 GDP growth and electricity intensity of Polish Economy [18]

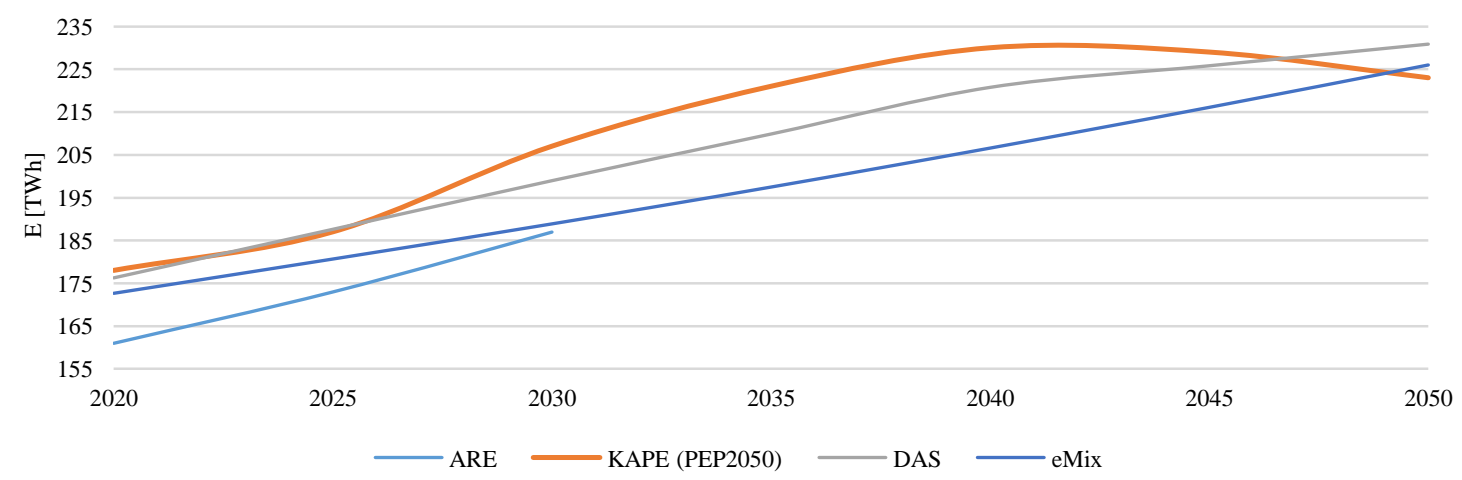

Figure 6 Future electricity demand in Poland according to ARE, Department of Strategic Analyses and assumptions in PEP2050 [21], [22] 


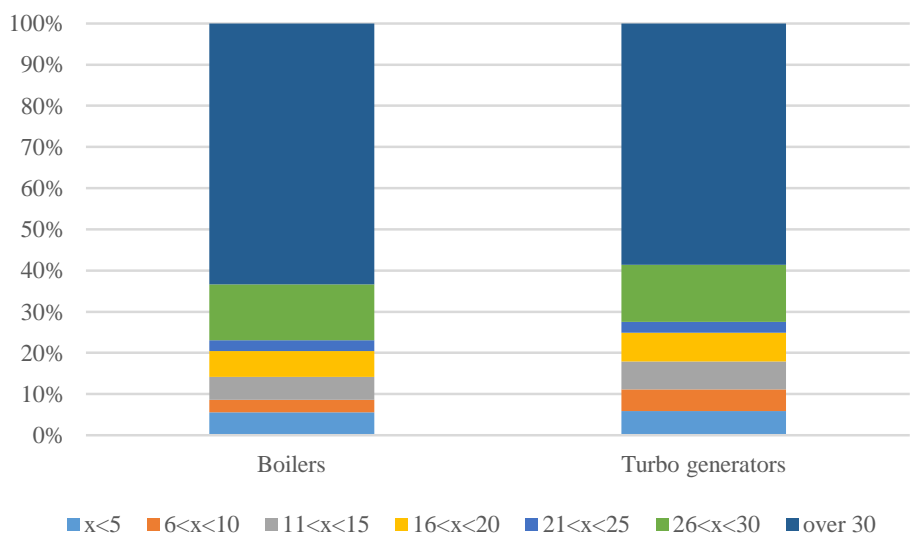

Figure 7 Age of boilers and turbo generators in Poland [23]

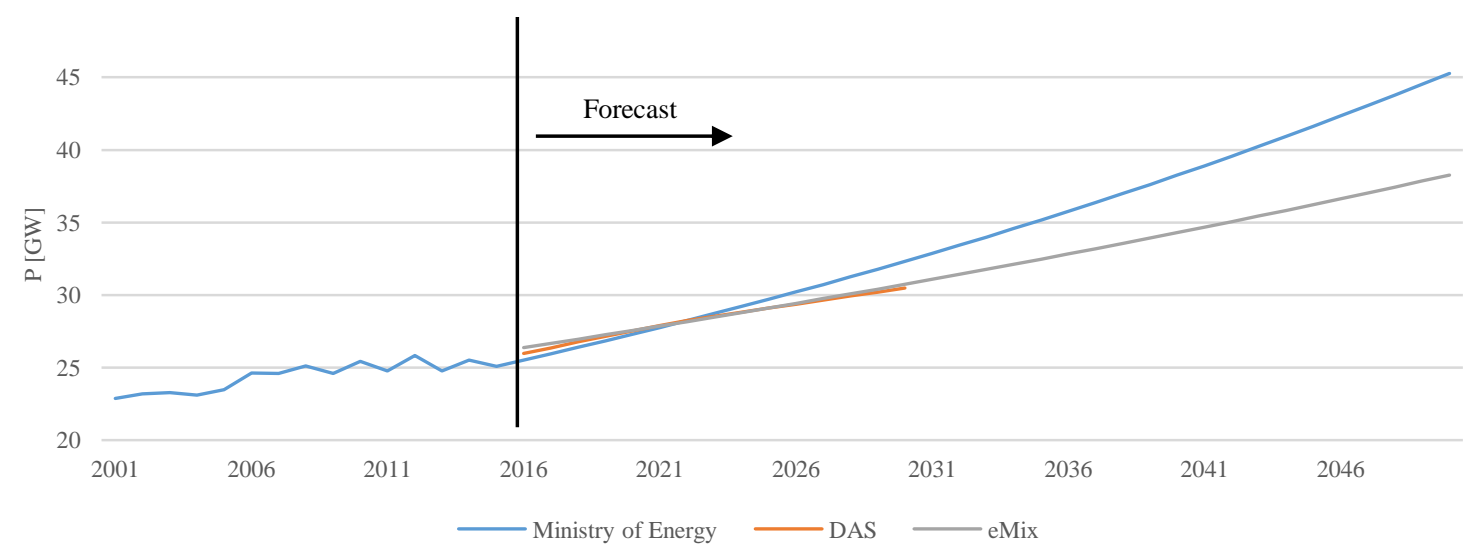

Figure 8 Historical data and forecast of power demand in Poland according to Ministry of Energy, Department for Strategic Analyses and own study [22], [27], [28]

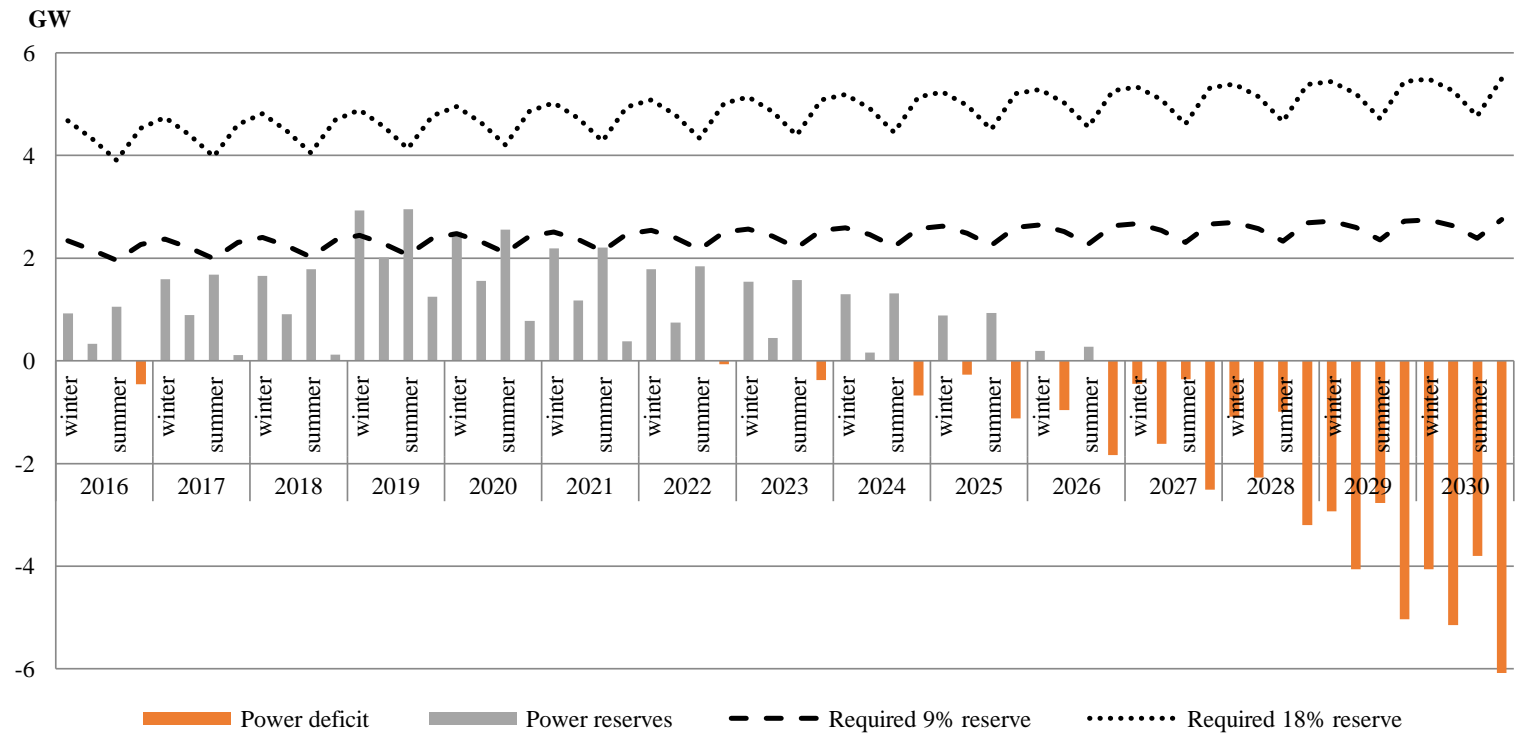

Figure 9 Reserves and power deficit (own development based on Polish TSO data [30]) 


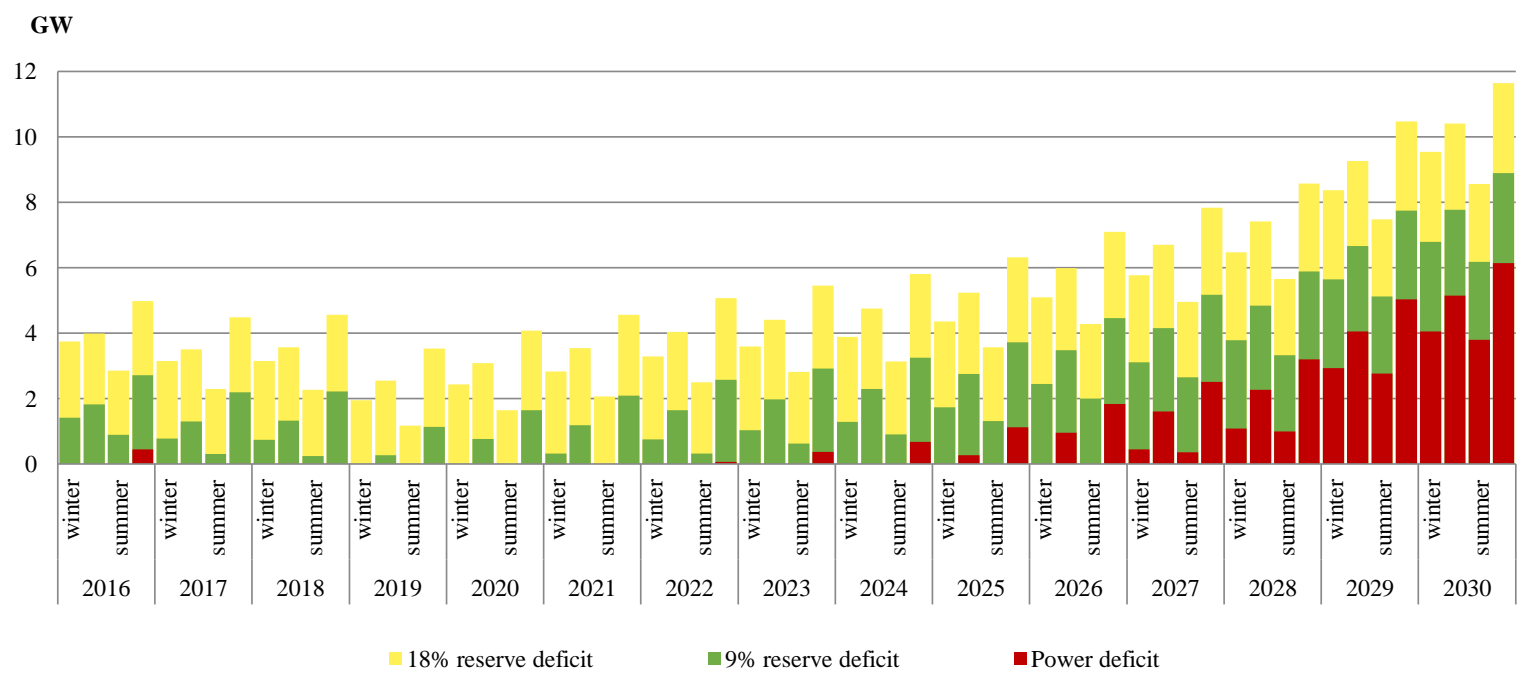

Figure 10 Power deficits (own development based on Polish TSO data [30])

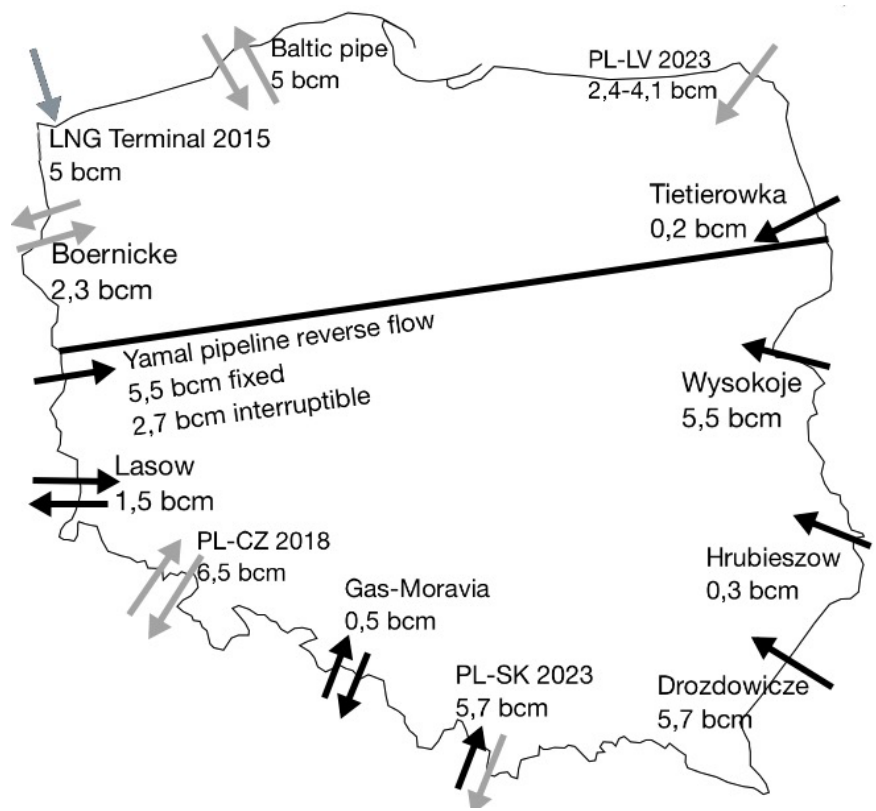

Figure 11 Gas interconnections: black - existing; grey - planned/under construction[109]-[111]
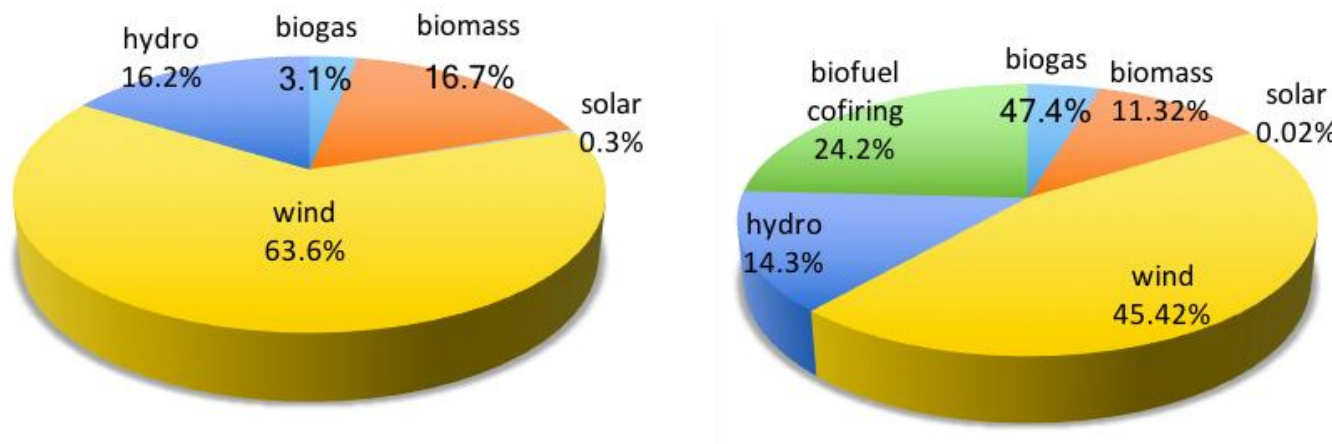

Figure 12 Structure capacity installed in RES (left) [60] and electricity generated by RES (right)[61] 

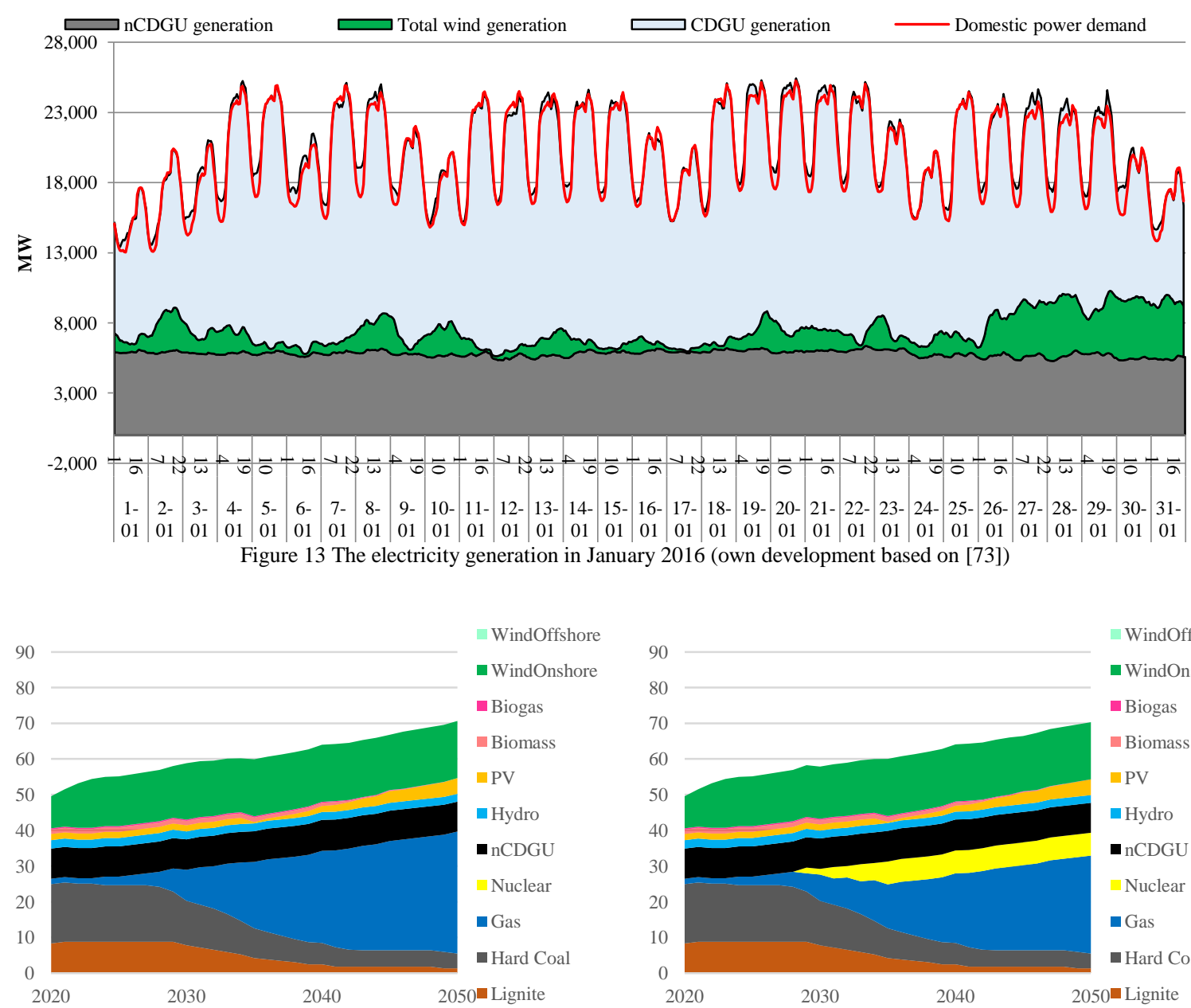

Figure 14 Installed power [GW] - S1

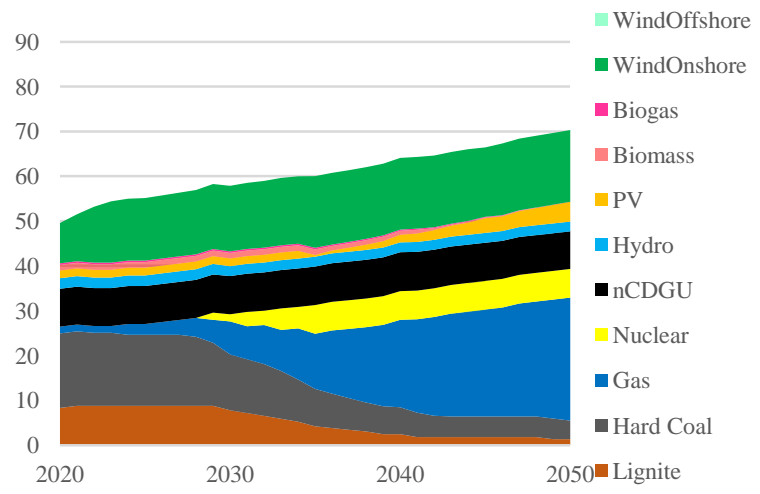

Figure 15 Installed power [GW] - S2

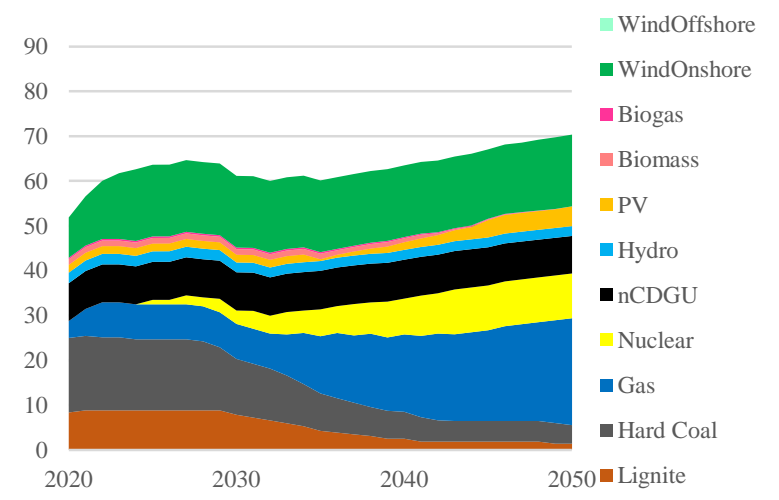

Figure 16 Installed power [GW] - S3
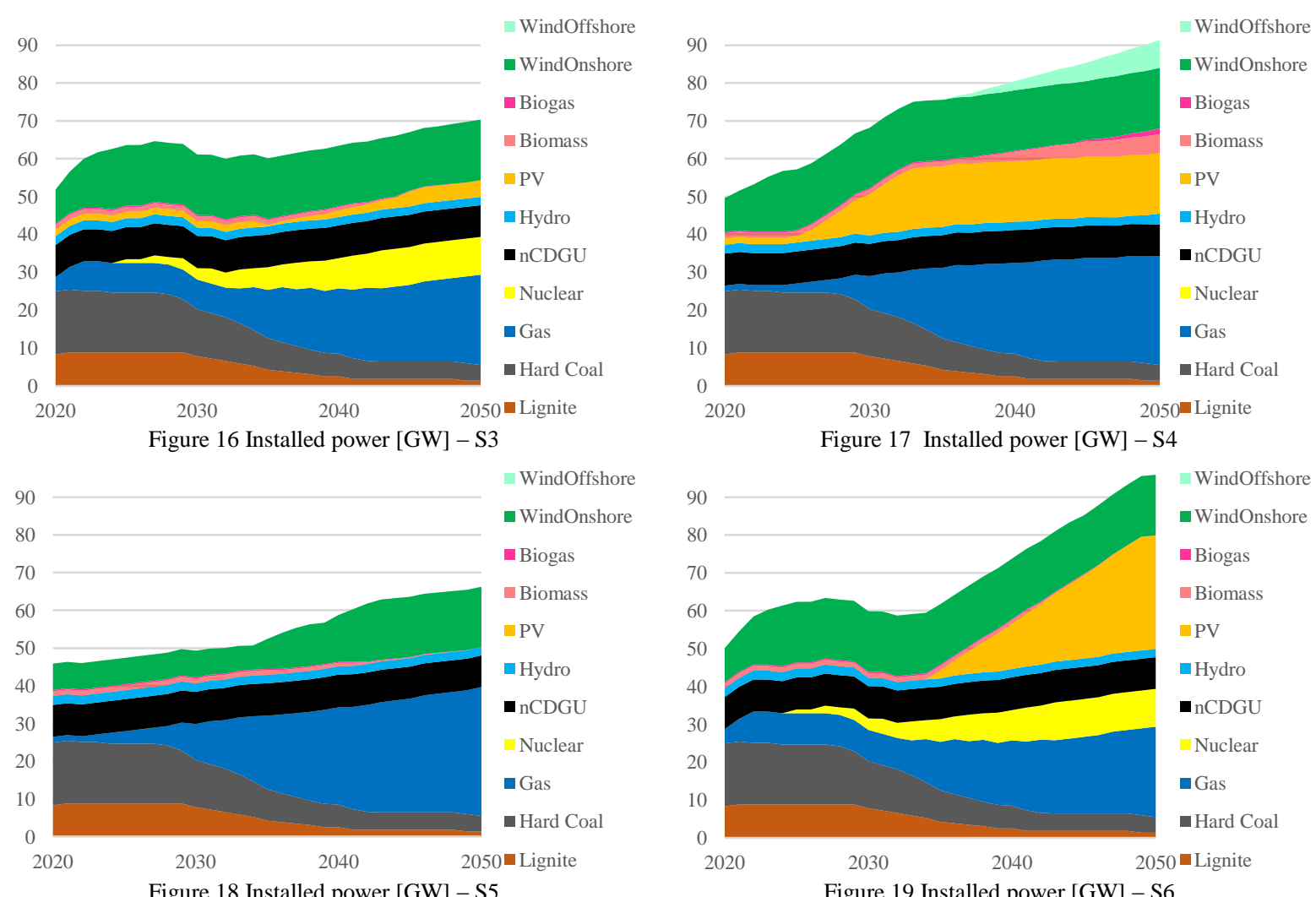

Figure 17 Installed power [GW] - S4

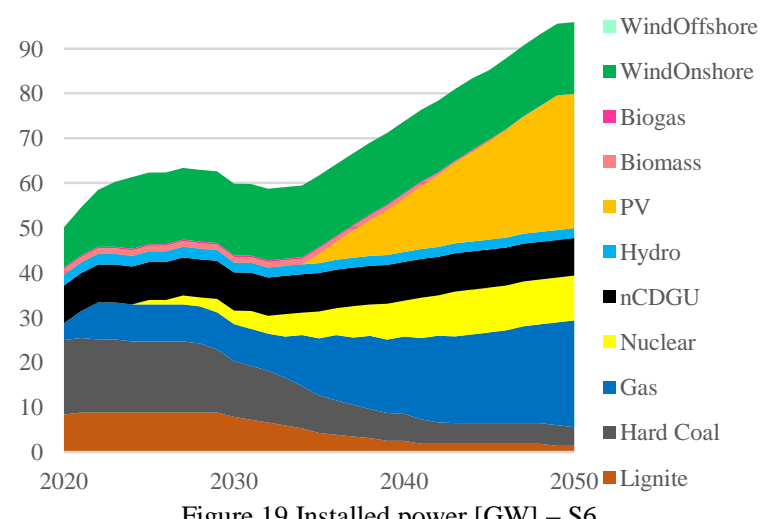



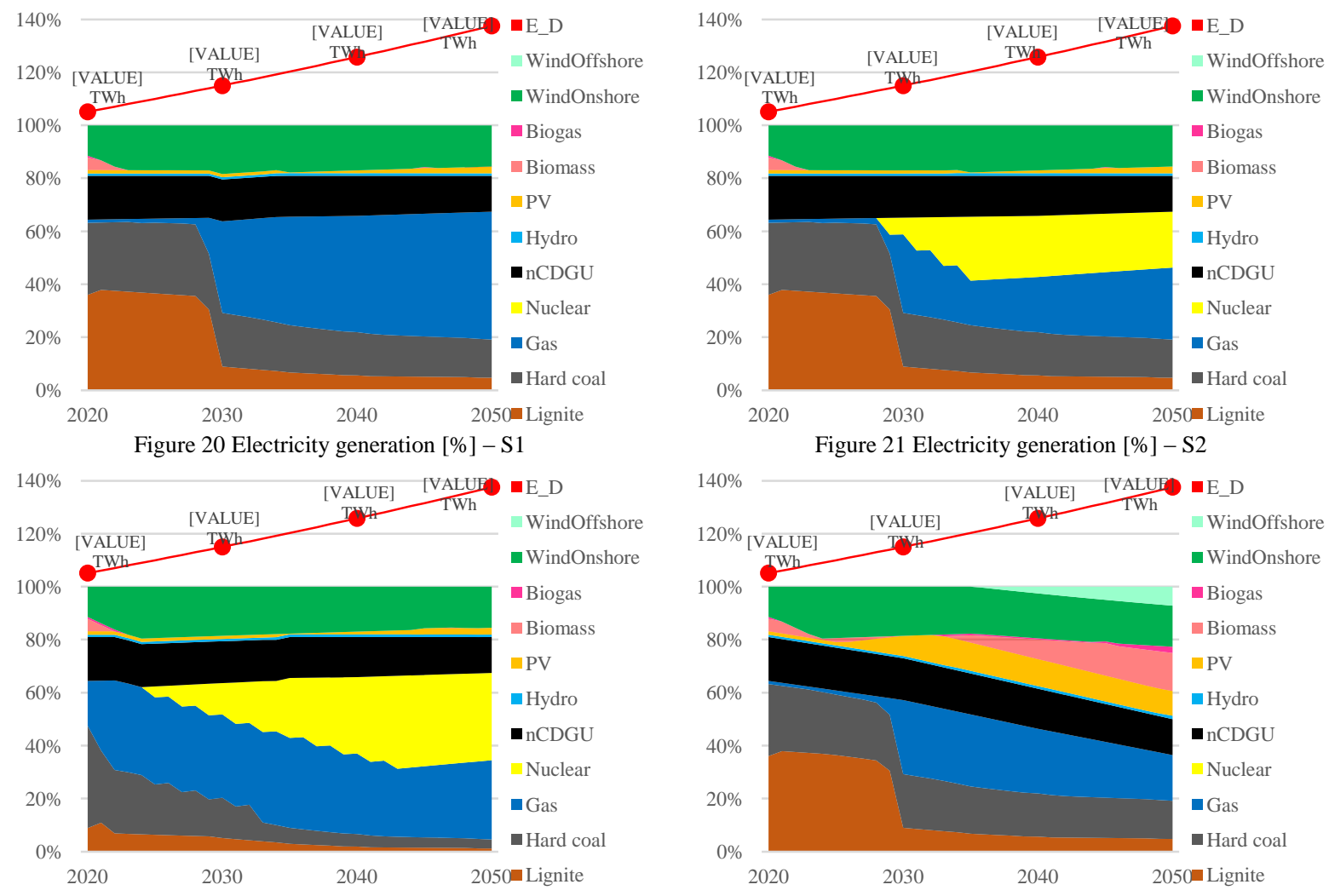

Figure 22 Electricity generation [\%] - S3

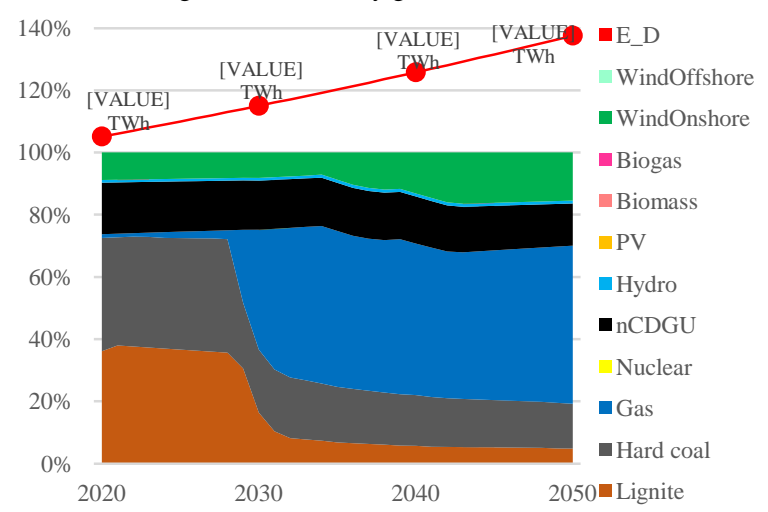

Figure 24 Electricity generation [\%] - S5

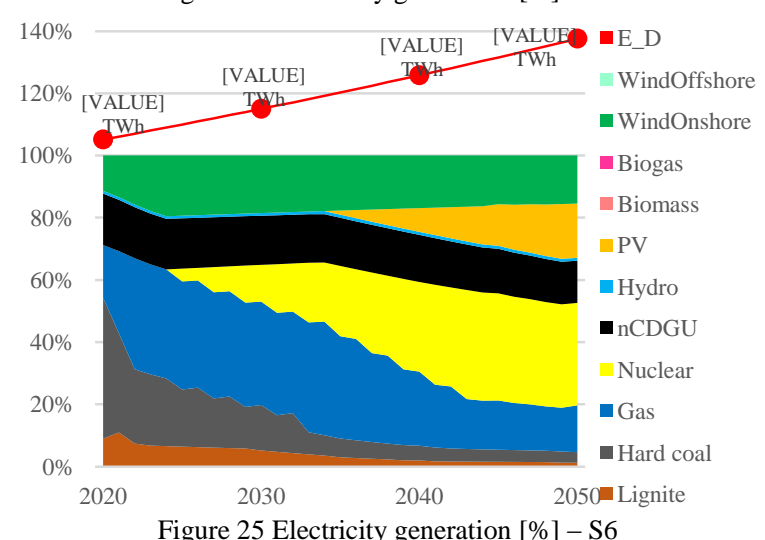

Figure 25 Electricity generation [\%] - S6

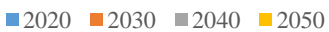

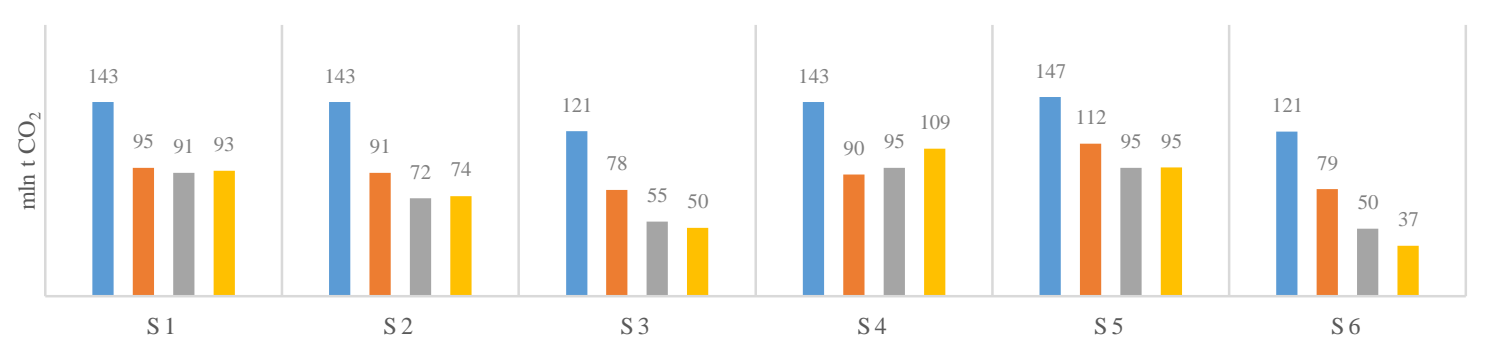

Figure $26 \mathrm{CO}_{2}$ emissions [mln t $\mathrm{CO}_{2}$ ] 


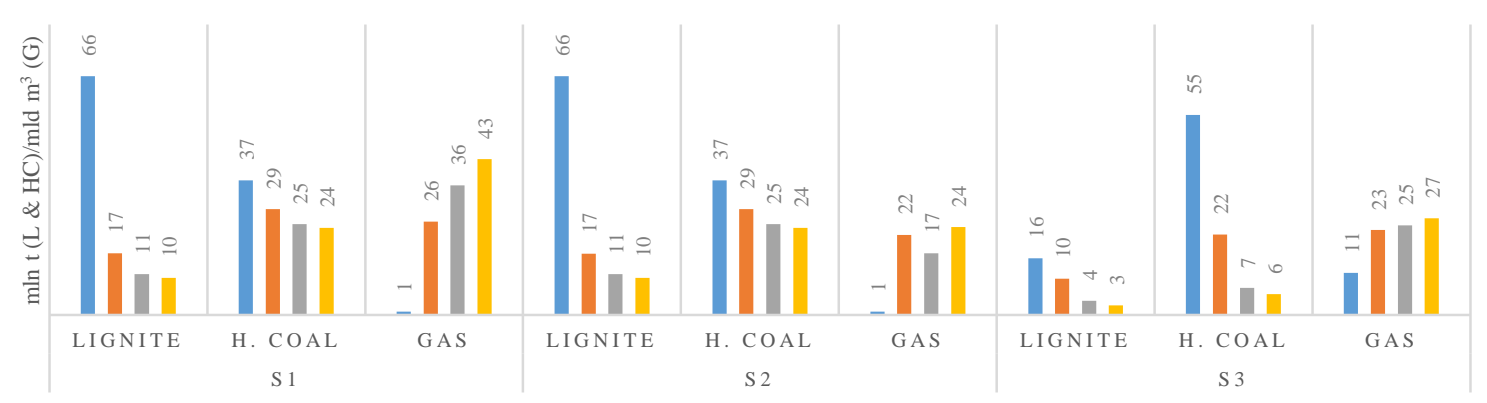

Figure 27 Primary fuel consumption [mln t] for lignite and hard coal; [ $\mathrm{mld} \mathrm{m}^{3}$ ] for gas - scenarios S1 - S3

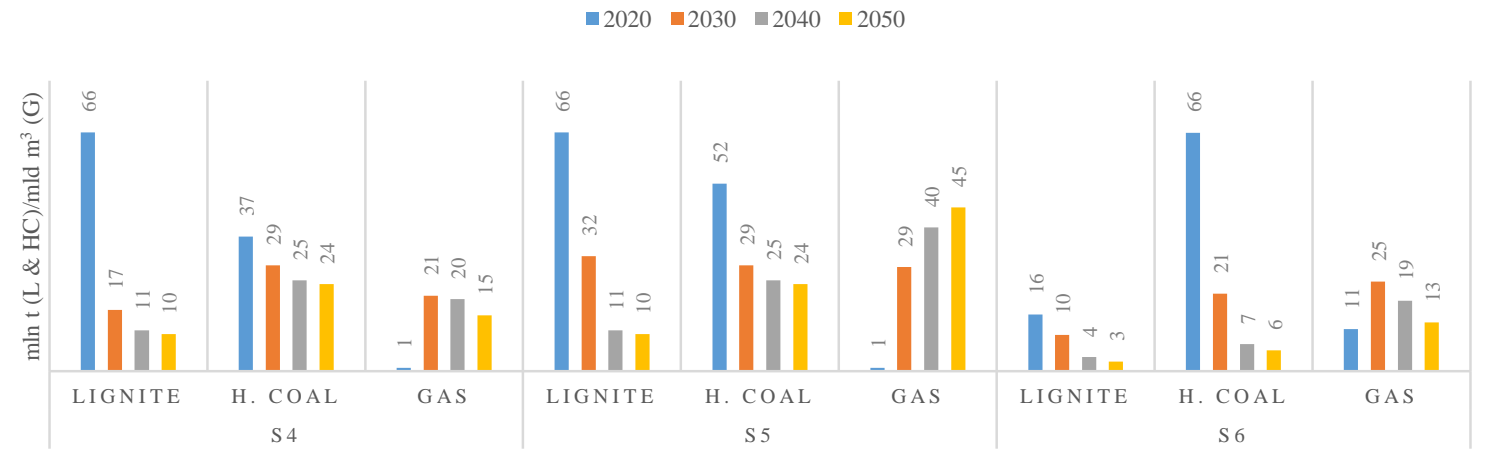

Figure28 Primary fuel consumption $[\mathrm{mln} \mathrm{t}]$ for lignite and hard coal; $\left[\mathrm{mld}^{3}\right]$ for gas - scenarios $\mathrm{S} 4-\mathrm{S} 6$

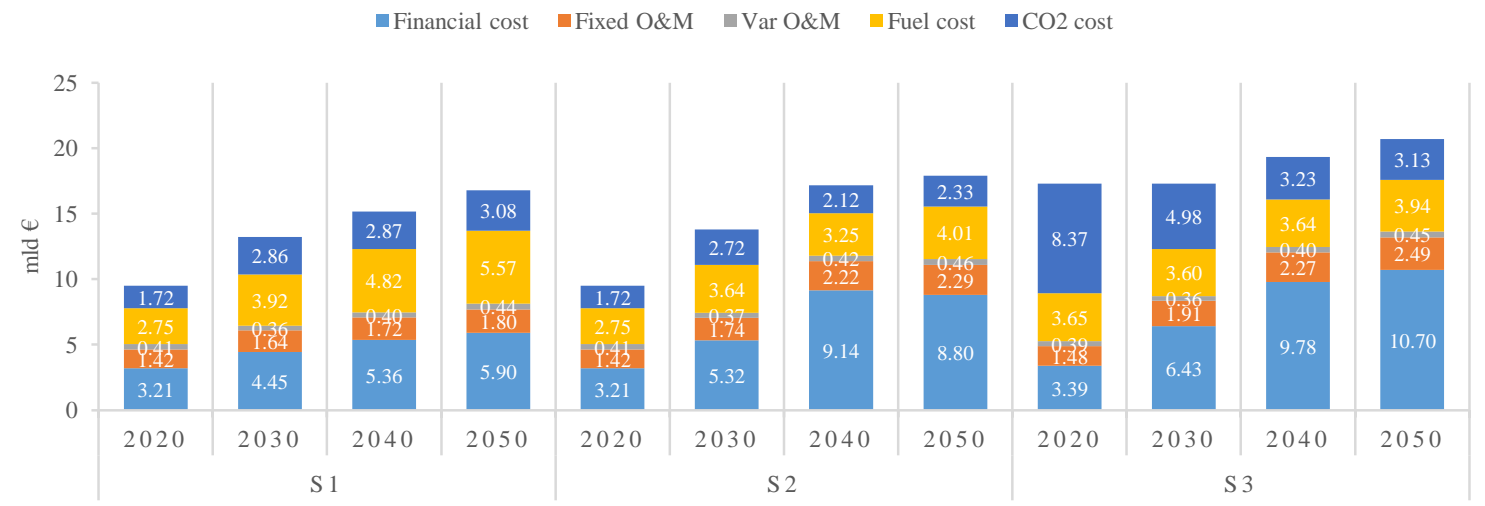

Figure 29 Total annual cost of electricity generation $[\mathrm{mln} €]-$ scenarios $\mathrm{S} 1-\mathrm{S} 3$

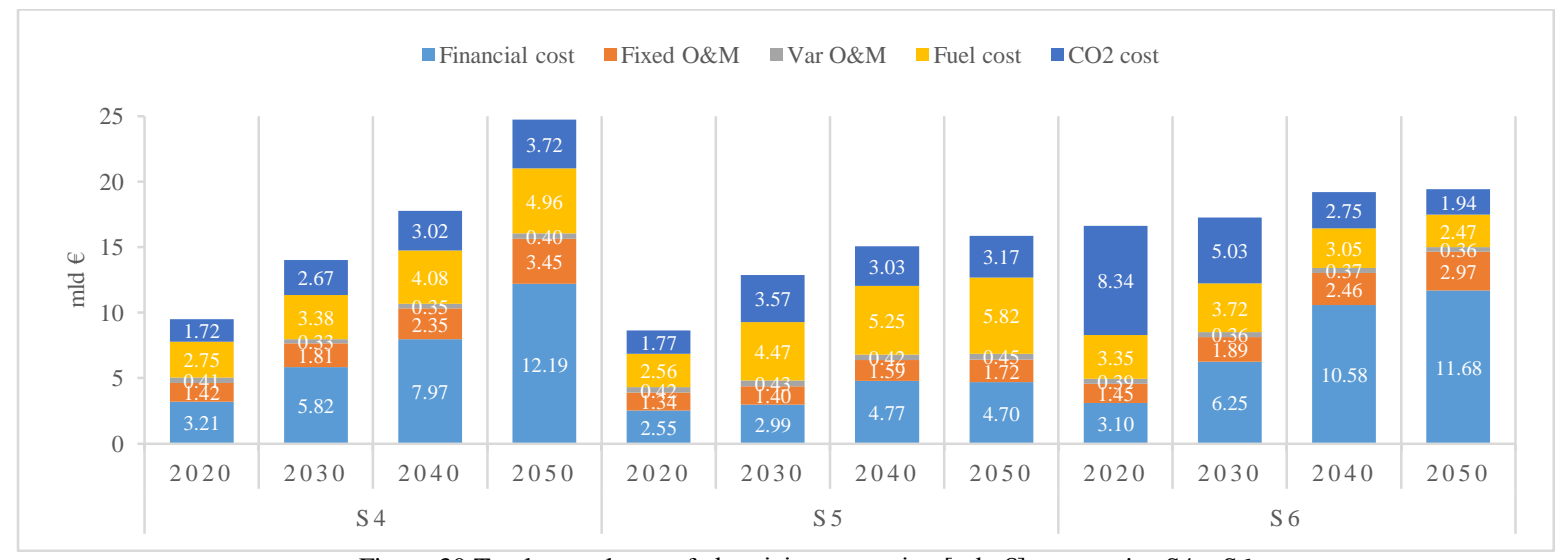

Figure 30 Total annual cost of electricity generation $[\mathrm{mln} €]-$ scenarios S4 - S6 


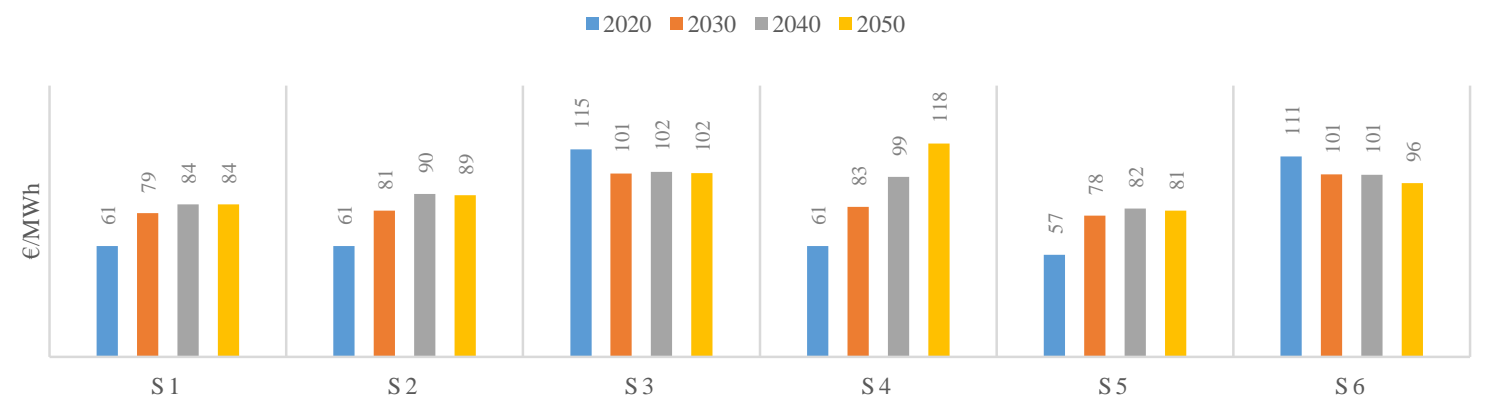

Figure 31. Marginal cost for electricity generation [€/MWh] 
Table 1 Comparison of energy policies for 2020 and 2030 targets [9].

\begin{tabular}{ll}
\hline $\mathbf{2 0 - 2 0 - 2 0}$ (enacted in 2009) & Energy policy 2020-2030 \\
\hline $20 \%$ of greenhouse gases reduction in comparison to 1990 & $40 \%$ of greenhouse gases reduction in comparison to 1990 \\
\hline $20 \%$ of share of RES in energy consumption (15\% for Poland) & $27 \%$ of share of RES in energy consumption \\
\hline $20 \%$ improvement in energy efficiency & $\begin{array}{l}27 \% \text { improvement in energy efficiency compared to the projected } \\
\text { efficiency for 2030 if the situation would not change }\end{array}$ \\
\hline
\end{tabular}

Table 2 Schedule of CDGU power plants decommissioning (own development)

\begin{tabular}{|c|c|c|c|c|c|c|c|}
\hline \multicolumn{2}{|l|}{ 2013-2020 } & \multicolumn{2}{|l|}{ 2021-2030 } & \multicolumn{2}{|l|}{$2031-2040$} & \multicolumn{2}{|l|}{ 2041-2045 } \\
\hline & MW & & MW & & MW & & MW \\
\hline Adamow & 600 & Jaworzno III & 1350 & Belchatow & 1870 & Belchatow & 1850 \\
\hline Belchatow & 740 & Kozienice & 675 & Dolna Odra & 908 & Opole & 763 \\
\hline Dolna Odra & 454 & Laziska & 905 & Kozienice & 1570 & Turów & 522 \\
\hline Kozienice & 660 & Ostroleka & 447 & Opole & 769 & Lagisza & 460 \\
\hline Lagisza & 360 & Polaniec & 450 & Patnow 1 & 880 & Siersza & 306 \\
\hline Laziska & 250 & Rybnik & 900 & Polaniec & 1125 & & \\
\hline Ostroleka B2 & 200 & & & Rybnik & 875 & & \\
\hline Patnow 1 & 400 & & & Turow & 966 & & \\
\hline Siersza & 360 & & & & & & \\
\hline Skawina & 440 & & & & & & \\
\hline Stalowa Wola & 240 & & & & & & \\
\hline Zeran & 244 & & & & & & \\
\hline$\Sigma$ & 4948 & $\Sigma$ & 4727 & $\Sigma$ & 8963 & $\Sigma$ & 3135 \\
\hline
\end{tabular}

Table 3 Polish interconnections [34], [40], [41]

\begin{tabular}{|c|c|}
\hline Interconnection & Capacity \\
\hline \multicolumn{2}{|l|}{ Germany } \\
\hline Krajnik - Vierraden & 2x408 MVA \\
\hline Mikulowa - Hagenwerder & 2x1386 MVA \\
\hline \multicolumn{2}{|l|}{ Czech Republic } \\
\hline Dobrzen - Albrechtice & 1386 MVA \\
\hline Wielkopole - Nosovice & 1386 MVA \\
\hline Kopanina/Bujakow - Liskovec & $2 \times 400$ MVA \\
\hline \multicolumn{2}{|l|}{ Slovakia } \\
\hline Krosno - Lemesany & 2x831 MVA \\
\hline \multicolumn{2}{|l|}{ Ukraine } \\
\hline Zamosc - Dobrotwor & 415 MVA \\
\hline Rzeszow - Chmielnicka & out of order \\
\hline \multicolumn{2}{|l|}{ Belarous } \\
\hline Bialysto - Ros & out of order \\
\hline \multicolumn{2}{|l|}{ Sweden } \\
\hline SwePol DC Link & $600 \mathrm{MW}$ \\
\hline \multicolumn{2}{|l|}{ Lithuania } \\
\hline LitPol DC Link & $500 \mathrm{MW}$ \\
\hline
\end{tabular}

Table 4 Hard coal and lignite resources in Poland [53]

\begin{tabular}{ll}
\hline Hard coal & \\
\hline In-balance: $\mathbf{5 1 , 4}$ billion $\mathbf{M g}$ & Recoverable: 19,5 billion $\mathrm{Mg}$ \\
\hline Out-of-balance: $\mathbf{1 9 , 1}$ billion $\mathbf{M g}$ & Non-recoverable: 27,9 billion $\mathrm{Mg}$ \\
\hline Lignite & Recoverable: 7,9 billion $\mathrm{Mg}$ \\
\hline In-balance: $\mathbf{2 2 , 7}$ billion $\mathbf{M g}$ & Non-recoverable: 10,5 billion $\mathrm{Mg}$ \\
\hline & \\
\hline Out-of-balance: $\mathbf{3 , 5}$ billion $\mathbf{M g}$ & Recoverable: 1,5 billion $\mathrm{Mg}$ \\
\hline & Non-recoverable: 21,2 billion $\mathrm{Mg}$ \\
\hline
\end{tabular}


Table 5 Average monthly prices in March 2016 in Poland [69]

\begin{tabular}{|l|l|l|}
\hline & $€ / \mathrm{MWh}$ & Description \\
\hline Monthly Base Price & 34.4 & Contract for 1 MWh of electricity supply for each hour of a day \\
\hline Monthly Peak Price & 37.78 & Contract for 1 MWh of electricity supply between 7:00 a.m.-10:00 p.m. \\
\hline Monthly Offpeak price & 28.02 & Contract for 1 MWh of electricity supply between 0:00-7:00 a.m. and 10:00 p.m-0:00 \\
\hline
\end{tabular}

Table 6. Key operational objectives of PEP 2050

\begin{tabular}{|c|c|c|}
\hline $\mathrm{I}$ & $\begin{array}{l}\text { Providing energy } \\
\text { security }\end{array}$ & $\begin{array}{l}\text { According to Polish law, the energy security is a state of economy that allows for covering the long-term } \\
\text { demand on fuels and energy in a technically and economically grounded manner. } \\
\text { To improve the energy security, it is important to focus on: } \\
\text { - Diversification of primary energy sources and their import directions } \\
\text { - Providing adequate capacity installed and diversification of the structure of final energy generation } \\
\text { - Effective utilization of domestic solid fuels sources (and their conservation to enable their extraction in } \\
\text { future) } \\
\text { - Stimulation of DSR development } \\
\text { - Preservation and development of transmission and distribution systems } \\
\text { - Defense of critical infrastructure }\end{array}$ \\
\hline II & $\begin{array}{l}\text { Increasing } \\
\text { competitiveness } \\
\text { and energy } \\
\text { efficiency of } \\
\text { Polish economy }\end{array}$ & $\begin{array}{l}\text { To improve the competitiveness and energy efficiency of polish economy, actions must be taken to: } \\
\text { - Rationalization of primary energy cost } \\
\text { - Development of the competitive electricity and gas markets in accordance with EU policies } \\
\text { - Improvement of energy efficiency in enterprises, heating systems and final energy use }\end{array}$ \\
\hline III & $\begin{array}{l}\text { Limiting the } \\
\text { impact of energy } \\
\text { sector on the } \\
\text { environment }\end{array}$ & $\begin{array}{l}\text { Limiting the impact of energy sector on environment can be achieved through: } \\
\text { - Limiting the greenhouse gases emissions } \\
\text { - Limiting the air, water and soil pollution } \\
\text { - Increasing the share of RES }\end{array}$ \\
\hline
\end{tabular}

Table 7. Prospective energy demand and peak load, own study based on ([22], [27], [107])

\begin{tabular}{ccccc}
\hline Years & $\mathbf{2 0 2 0}$ & $\mathbf{2 0 3 0}$ & $\mathbf{2 0 4 0}$ & 2050 \\
\hline Energy demand [TWh] & 172.7 & 188.9 & 206.6 & 226.0 \\
\hline Peak load $[\mathbf{M W}]$ & 27562 & 30748 & 34303 & 38268 \\
\hline
\end{tabular}

Table 8. Scenarios definition

\begin{tabular}{|c|c|c|c|c|c|}
\hline No & Description & $\begin{array}{c}\text { EUA } \\
\text { price } \\
{\left[€ / \mathbf{C O}_{2}\right]}\end{array}$ & $\begin{array}{c}\text { RES } \\
\text { requirement }\end{array}$ & $\begin{array}{c}\text { Execution of nuclear } \\
\text { program (political } \\
\text { decision) }\end{array}$ & $\begin{array}{c}\text { RES learning } \\
\text { rates }\end{array}$ \\
\hline S1 & Reference scenario - Business as Usual & $15-40$ & $19 \%$ (all horizon) & NO & NO \\
\hline $\mathbf{S 2}$ & Polish Nuclear Power Program & $15-40$ & $19 \%$ (all horizon) & YES & NO \\
\hline S3 & High EUA price & 90 & $19 \%$ (all horizon) & $\mathrm{NO}$ & NO \\
\hline S4 & High RES share & $15-40$ & $\begin{array}{c}19 \%, 27 \%, 50 \% \\
(2020,2030,2050)\end{array}$ & NO & $\mathrm{NO}$ \\
\hline S5 & Reference scenario with learning rates & $15-40$ & $\mathrm{NO}$ & $\mathrm{NO}$ & YES \\
\hline S6 & High EUA price with learning rates & 90 & $\mathrm{NO}$ & $\mathrm{NO}$ & YES \\
\hline
\end{tabular}

Table 9. The potentials and learning rates for RES [22]

\begin{tabular}{cccccc}
\hline Parameter & Hydro & PV & Biomass & Biogas & $\begin{array}{c}\text { Wind } \\
\text { onshore }\end{array}$ \\
\hline Potential [MW] & 3000 & $16000^{*}$ & 15000 & 7000 & 16000 \\
\hline offshore & 8000 \\
\hline Lax. annual capacity increase [MW] & 1500 & 2000 & 1700 & 250 & 2000 \\
\hline Learning rate [-] & - & $2.2 \%$ & - & $0.9 \%$ & $1.2 \%$ \\
\hline for scenarios S5 and S6 PV potential is unlimited & & & $0.3 \%$ \\
\hline
\end{tabular}

* for scenarios S5 and S6 PV potential is unlimited 